\title{
Determinants of Electric Vehicle Diffusion in China
}

\author{
Martin Kalthaus $^{1}$ (D) . Jiatang Sun ${ }^{1}$
}

Accepted: 4 August 2021 / Published online: 26 August 2021

(c) The Author(s) 2021

\begin{abstract}
We analyze the effect of four determinants of electric vehicle diffusion in China for a panel of 31 regions for the period 2010-2016. We analyze diffusion of four different electric vehicle types, namely battery electric cars and buses as well as plug-in hybrid electric cars and buses. System GMM panel estimation results show that total monetary subsidies have a positive effect only on the diffusion of battery electric cars. A closer look reveals that subsidies provided by regional governments are decisive for all types of vehicles but the subsidy provided by the central government and its degression over time dilute the overall effect of subsidies and is partly detrimental. Non-monetary ownership policies, such as license-plate lotteries, show a positive effect only for battery electric cars. Availability of public charging infrastructure increases diffusion of all vehicle types. Charging points are relevant for cars, while charging stations are especially decisive for the diffusion of electric buses. Using local environmental conditions as a novel determinant for the diffusion of electric vehicles reveals that the local air pollution influences the diffusion of buses, but not of cars.
\end{abstract}

Keywords Electric vehicle $\cdot$ Diffusion $\cdot$ Eco-innovation $\cdot$ China $\cdot$ Innovation policy

JEL Classification $\mathrm{L} 98 \cdot \mathrm{O} 31 \cdot \mathrm{O} 33 \cdot \mathrm{Q} 48$

\section{Introduction}

Electric vehicles are perceived as a way to mitigate environmental externalities and they have the potential to disrupt the automotive industry. Even though electric vehicles have a long tradition, they never diffused on larger scale until recently. IEA (2019) counts more than five million registered electric cars globally in 2018. China is the leading country in

Martin Kalthaus

martin.kalthaus@uni-jena.de

1 Department of Economics, Friedrich Schiller University Jena, Carl-Zeiß-Straße 3, 07743 Jena, Germany 
terms of absolute number of electric cars, with a share of about $45 \%$ of global electric cars. China also has the largest electric bus fleet in operation, with $99 \%$ of electric buses worldwide (Bloomberg New Energy Finance 2018). ${ }^{1}$ However, compared to the overall stock of vehicles and their potential to address local and global environmental problems, the number of electric vehicles needs to increase substantially and substitute vehicles with internal combustion engine in the next years (Sims et al. 2014). The increasing use of electric vehicles is one of the requirements to achieve the $1.5{ }^{\circ} \mathrm{C}$ goal to reduce the impact of climate change (IPCC 2018).

Diffusion of electric vehicles is impeded by several shortcomings compared to conventional vehicles with internal combustion engine. Foremost, electric vehicles face disadvantages due to higher initial purchasing costs (Weiss et al. 2012; Zhao et al. 2015) and total cost of ownership (Falcão et al. 2017; Palmer et al. 2018). Furthermore, their technological development is not as advanced as the one for internal combustion engine vehicles. In particular, the batteries powering the vehicles require substantial technological improvements. This technological disadvantage leads to lower utility, since range is reduced and charging is time-consuming. Also, charging opportunities are not as frequently available as gas stations for conventional vehicles. Customers perceive the reduced range and possible lack of charging infrastructure as a major disadvantage and "range anxiety" reduces their willingness to purchase electric vehicles (Egbue and Long 2012; Coffman et al. 2016). Lastly, the automotive industry is locked-in into the production of conventional vehicles and efforts to innovate in electric vehicles are reduced (Cowan and Hulten 1996; Unruh 2000). To overcome these monetary and technological disadvantages of electric vehicles, policy makers implemented various instruments to foster their diffusion. Policy makers' intention to support the diffusion of electric vehicles not only aims to improve local and global environmental conditions, but it is also motivated by industrial policy considerations (Lane et al. 2013).

The tremendous increase in electric vehicle diffusion in China can be attributed to such governmental interventions. Since the 1990s, the Chinese government has placed the development and diffusion of electric vehicles high on its political agenda (Gong et al. 2013; Yuan et al. 2015; Zhang and Bai 2017). First, China wants to establish an industry base to leapfrog conventional technologies and claim global leadership in the electric vehicle market (Wang and Kimble 2011; Howell et al. 2014). Second, China sees electric vehicles as means to address local pollution and improve local air quality (Zheng et al. 2012). Third, China wants to mitigate climate change and electric vehicles are a potential approach. To foster the diffusion of electric vehicles, several policy instruments were implemented on the national as well as on the regional level (Zhang and Bai 2017; Zhang et al. 2017).

This paper analyzes different determinants for the diffusion of electric vehicles in China. The heterogeneous policy instruments implemented at the central and regional government level make China an interesting case to understand which policy instruments and conditions influence electric vehicle diffusion. Based on a theoretical discussion of the factors influencing the diffusion of environmental innovations and the emerging literature on the diffusion of electric vehicles, we derive four hypotheses: we hypothesize that monetary as well as non-monetary incentives, availability of public charging infrastructure and the local environmental conditions have an effect on the diffusion of electric vehicles.

\footnotetext{
1 China is also the largest market for electric two- and three-wheelers, with a global market share of about 99\% and a stock of 250 and 50 million respectively (IEA 2019). For a detailed assessment of two-wheelers in China, see Wells and Lin (2015) or Zuev (2018).
} 
We test the influence of these four possible determinants on four different electric vehicle types. We separate electric vehicles into two categories based on their engines - Battery Electric Vehicles (BEV) and Plug-in Hybrid Electric Vehicles (PHEV). BEV run solely on an electric engine, while PHEV have both an electric engine and an internal combustion engine, which can power the vehicle if the battery is empty. We further differentiate between vehicle types, namely cars and buses. Since China is also the world leader in electric buses (IEA 2019), new insights can be derived from a comparative analysis of different vehicle types. We use a System Generalized Method of Moments (GMM) estimation approach to account for the dynamic nature of the diffusion process and to tackle endogeneity issues, especially with respect to subsidies and charging infrastructure. Our analysis covers the period 2010-2016 for 31 Chinese regions (cities and provinces) mainly in the eastern part of the country.

Our results provide a detailed and heterogeneous picture of the determinants of electric vehicle diffusion in China. The distinction among four different vehicle types reveals that policy instruments do not affect vehicle types equally. The total subsidy amount is especially relevant for BEV cars. However, differentiating between regional and central government subsidies reveals that the regional subsidy level has a positive effect for all vehicle types, while the central government subsidy, which decreases over time, has in some cases an adverse effect. Public charging infrastructure is relevant for the diffusion of all vehicle types and charging stations are especially relevant for electric buses. Non-monetary incentives such as license-plate lotteries or auctions show an effect only for BEV cars. Local air pollution only has an effect on the diffusion of buses, but not on cars. With the latter result we provide, to our knowledge, the first empirical assessment of environmental conditions on diffusion. We show that in specific cases, here the diffusion of buses, bad environmental conditions can increase diffusion of environmentally friendly innovations. However, one needs to keep in mind that these buses are usually purchased by regional governments and are most likely part of a larger effort to address local pollution via green public procurement (Aldenius and Khan 2017). In terms of research on the diffusion of electric vehicles, we provide the first empirical assessment of the diffusion of buses, a highly relevant case neglected so far in empirical analysis. We furthermore provide policy recommendations on the diffusion of electric vehicles in particular and for environmentally friendly innovations in general.

In the following Sect. 2 we provide a theoretical discussion about the diffusion of environmentally friendly innovations and derive four hypotheses for determinants of electric vehicle diffusion. Section 3 provides insights on electric vehicle diffusion in China as well as Chinese environmental conditions. In Sect. 4, we discuss our data and estimation strategy and we provide regression results. In Sect. 5 we discuss the results and conclude.

\section{Literature Review}

\subsection{Diffusion of Environmentally Friendly Technologies}

The process of diffusion of innovations into economic application has been a subject for economic analysis since the seminal contributions by Griliches (1957) and Rogers (1962). Several stylized facts and diffusion models have been proposed since then (see Metcalfe 1988; Geroski 2000; Hall 2006, for surveys). Most striking is the observation of a S-shaped diffusion curve with respect to the share of adoption over time. Of particular interest from 
an economic point of view are the determinants of the rate of diffusion. Hall (2006) categorizes factors influencing the rate of diffusion into four groups: the benefits from adoption, costs for adoption, factors related to the industrial and social environment, as well as uncertainty and information problems. While these determinants are relevant for all innovations, there is a distinct group of innovations which are subject to additional factors: environmentally friendly innovations (see Cecere et al. 2014, for an overview of different definitions).

Research on environmentally friendly innovations, or short eco-innovations, and their diffusion has received much attention lately (Karakaya et al. 2014). Such innovations have reduced or no environmental externalities and are possible means to mitigate climate change. However, they suffer from a so-called double externality problem, which reduces their diffusion rate (Rennings 2000; Jaffe et al. 2005). The underlying problem relates to two market failures which are present simultaneously for eco-innovations. On one hand, eco-innovations suffer from knowledge externalities that reduce innovative activity (Arrow 1962). On the other hand, they face disadvantages compared to technologies which do not internalize external effects on the environment (Baumol and Oates 1988). In a setting where an eco-innovation competes with a non-eco-innovation, innovation activity and diffusion are reduced for the eco-innovation, creating a negative feedback which results in a lock-in situation that usually favors the environmentally unfriendly solution (Arthur 1989; Cowan and Hulten 1996; Unruh 2000). To overcome such a lock-in situation and to increase diffusion of eco-innovations, policy intervention is necessary (Unruh 2000, 2002; Cecere et al. 2014).

Besides the double externality problem, other factors can influence the diffusion of eco-innovations. For example, environmentally aware customers have higher preferences towards a clean environment and exhibit a higher willingness to pay for products and services which do not influence the environment (or to a lesser extend). Extreme forms are sometimes referred to as green- or eco-worriers (Windrum et al. 2009; Williams 2013), who can be seen as lead users or early adopters supporting eco-innovations early on. Empirical evidence suggests that customer preferences for a clean environment can increase diffusion of eco-innovations. For example, customers are willing to pay more for electricity that is generated from renewable sources (Sundt and Rehdanz 2015). Also, sustainable consumption and lifestyles (Spaargaren 2003) as well as the consumer's perception of an eco-innovation towards her values, identity and norms (Ozaki 2010) can increase the diffusion of eco-innovations.

From a theoretical point of view on the determinants of eco-innovation diffusion, Cantono and Silverberg (2009) model the diffusion of eco-innovation and analyze the effect of green preferences and purchase subsidies on the speed of diffusion. In their percolation model, in which customers have heterogeneous preferences for green technologies, they show that subsidies increase diffusion and technological learning effects take place, increasing diffusion further. Without subsidies, customers with green preferences are not enough to increase diffusion. This result is similar to the findings by Herrmann and Savin (2017), who model the diffusion of renewable energy technologies in Germany. They show that a specific mix of instruments leads to a cost-efficient support of diffusion and that green preferences alone are not sufficient for a self-sustained diffusion path.

\subsection{Factors Influencing the Diffusion of Electric Vehicles}

Electric vehicles are considered an eco-innovation that have a very low diffusion rate, despite their long history (IEA 2019). They have great potential to reduce local and global 
emissions (Sperling 2018). This potential is however not utilized because the automotive sector is locked-in into the usage of the internal combustion engine (Cowan and Hulten 1996; Unruh 2000). However, the diffusion rate increased recently and until 2018 more than five million electric cars were in use (IEA 2019). The factors that helped to overcome the lock-in and to increase the diffusion rate of electric vehicles are of particular interest to foster the diffusion of electric vehicles and eco-innovations in general. In the following, four key factors that potentially influence the diffusion of electric vehicles are discussed. ${ }^{2}$

An economic argument to explain the low diffusion of electric vehicles involves their relative price compared to vehicles with an internal combustion engine (Weiss et al. 2012; Zhao et al. 2015) and the total cost of ownership, which can be substantially higher than for conventional vehicles (Falcão et al. 2017; Palmer et al. 2018). Due to knowledge accumulation and the realization of economics of scale, vehicles with internal combustion engine have a higher level of development and lower unit cost. Electric vehicles are comparatively costly, since they could not rely on economies of scale and feedback effects to the same extend. Furthermore, they are subject to the double externality problem, which reduces the incentive to invest in $\mathrm{R} \& \mathrm{D}$ and in turn could increase cost reductions. To overcome this disadvantage compared to vehicles with an internal combustion engine, governments can grant subsidies to purchase electric vehicles, reducing the relative price difference and thereby fostering diffusion. Cantono and Silverberg (2009) show in their diffusion model that subsidies which reduce the high upfront cost are indeed able to increase diffusion and induce learning effects, resulting in price reduction until the diffusion is self-sustained and subsidies are no longer required.

This relationship is supported by broader empirical evidence. Hardman et al. (2017) review 35 empirical studies that either analyze the influence of subsidies-which can be point of sale grants, income or value added tax incentives, post purchase rebates, or others-on diffusion or the perceptions of potential customers towards electric vehicles. They find that in most studies, subsidies have a positive influence on diffusion or the willingness to purchase an electric vehicle. However, subsidies need to be targeted to the customer. For example, Tal and Nicholas (2016) find for US customers that incentives are especially relevant for low-end cars, while high-end electric cars are purchased anyway (see also Hardman and Tal 2016, for a detailed survey of motives for high-end electric car owners). Jenn et al. (2013) show that in the US, hybrid electric vehicle incentives need to be sufficiently large to increase diffusion, but Sheldon and Dua (2019) show that subsidy efficiency can be improved if the subsidy level is dependent on customer income and vehicle characteristics. For the US, a $\$ 1000$ increase in rebates or tax credits increases average electric vehicle sales by $2.6 \%$ according to Jenn et al. (2018), by $5 \%$ to $11 \%$ according to Wee et al. (2018) who account for vehicle differences in US states and by $8 \%$ according to Clinton and Steinberg (2019). Münzel et al. (2019) find for a panel of 32 European countries that a subsidy increase of $€ 1000$ would increase vehicle sales shares relatively by $5-7 \%$. With respect to China, Ma et al. (2017) and Li et al. (2019) show significant effects of purchase subsidies on electric vehicle diffusion across Chinese cities. However, Wang et al. (2017a) find no significant effect of purchase subsidies on diffusion across Chinese cities. With respect to the overall evidence of the effect of purchase subsidies, we therefore hypothesize:

\footnotetext{
${ }^{2}$ For a review of further factors such as vehicle characteristics, customer preferences, and social norms, see Coffman et al. (2016) and Kumar and Alok (2020).
} 
H1: Financial purchase incentives have a positive effect on the diffusion of electric vehicles.

Besides financial incentives, governments can implement non-monetary regulations to either support a technology or to regulate or even prohibit competing ones. Standards and regulations are instruments frequently used to increase diffusion of eco-innovations (see Jaffe et al. 2003, for an overview). In the case of electric vehicles, instruments such as quotas have been implemented in California, for example (Kemp 2005). Other regulations can also increase the willingness of customers to adopt, for instance, preferred treatments on roads (e.g. special lane access), free parking, exemption from driving restrictions and other favorable conditions with respect to conventional vehicles (Coffman et al. 2016). Hardman (2019) provides an overview of different regulatory incentives to promote the diffusion of electric vehicles.

Empirical evidence in Gallagher and Muehlegger (2011) show mixed findings for the correlation between the allowance of high occupation lane use by electric vehicles and their diffusion in the US. In the case of China, Ma et al. (2017) show that the abolition of restriction on traffic for electric vehicles in Chinese cities increase diffusion and Wang et al. (2017b) and Li et al. (2019) find a strong effect of license-plate lotteries and no driving restriction on electric vehicle diffusion in Chinese regions. Based on the general literature on regulations and first empirical insights, we hypothesize:

H2: Regulatory incentives have a positive effect on the diffusion of electric vehicles.

The diffusion of innovations is not only related to its own characteristics but also to complementary factors, especially infrastructure (Rosenberg 1972). Indirect network effects increase the utility that can be derived from a good due to the presence of complementary goods (Katz and Shapiro 1994). Complementary infrastructure is especially an issue in the mobility sector. Gnann and Plötz (2015) review the empirical and theoretical literature with respect to complementary infrastructure for alternative engine vehicle diffusion. For electric vehicles, charging infrastructure is especially relevant, since until now, the range of electric vehicles is comparably low and customers face range anxiety and fear that without sufficient charging infrastructure they cannot fully utilize the vehicle (Egbue and Long 2012). Bleda and del Rio (2013) warn about the high potential of coordination failure which would reduce utility if sufficient complementary infrastructure is not present.

Several empirical studies find a strong correlation between the presence of charging infrastructure and electric vehicle diffusion. Sierzchula et al. (2014) show for a cross-section of 30 countries that charging infrastructure plays a major role in electric mobility diffusion. Such results are also present on the country level: Vergis and Chen (2015) show them for the US; Mersky et al. (2016) for Norway; and Egnér and Trosvik (2018) for Sweden and also address potential endogeneity issues. Li et al. (2017) model the bi-directional relationship between the provision of charging infrastructure and vehicle sales in the US. They estimate an elasticity of vehicle diffusion and charging infrastructure of 0.84 and the elasticity of charging infrastructure and the stock of electric vehicles of 0.61 , demonstrating substantial indirect network effects. In the case of China, Wang et al. (2017a) and Li et al. (2019) provide evidence for a positive relationship. The overall theoretical and empirical evidence leads to the hypothesis: 
H3: Availability of charging infrastructure has a positive effect on the diffusion of electric vehicles.

While the first three hypotheses influence the price or utility derived from an electric vehicle, customers might also purchase electric vehicles because they have preferences for the environment or their health. Since electric vehicles produce no tailpipe pollution they can be seen as means to improve the environment and reduce hazardous local air pollution (Sperling 2018). Customers' preferences for the environment can increase their willingness to pay for an electric vehicle compared to a vehicle with an internal combustion engine. Such green customer preferences are, for example, modeled in Cantono and Silverberg (2009) and these customers are usually early adopters (Windrum et al. 2009; Williams 2013). Several willingness to pay surveys show how preferences with respect to the environment influence consumption decisions for electric vehicles. Bunch et al. (1993) show that customers are willing to pay a premium for electric vehicles if they have considerable environmental benefits compared to gasoline vehicles. Similar results are presented by Erdem et al. (2010) who show that customers in Turkey who are concerned about global warming have a higher willingness to pay for hybrid cars. Carley et al. (2013) finds that the environmental view of survey participants in the US has a positive effect on their intent to purchase a plug-in electric vehicle. Hardman and Tal (2016) survey high-end electric vehicle owners in the US and find that environmental concerns were mentioned by more than $50 \%$ of vehicle owners. Contrary to these findings, Hidrue et al. (2011) find that among several characteristics, the environmental improvements associated with electric vehicles exhibit the lowest willingness to pay. Also, Figenbaum and Kolbenstvedt (2016) survey electric vehicle owners in Norway and environmental benefits were among the least relevant factors for their purchasing decision.

Due to the severe environmental conditions in China, the willingness to pay for environmental improvements are large in general. Freeman et al. (2019) show that households in China have a high willingness to pay for clean air revealed by relocation to less polluted areas. Similarly, Chen et al. (2017) demonstrates that high levels of pollution induce costly migration decisions for Chinese households. To actively address pollution, Ito and Zhang (2020) show that Chinese people are investing in home air purifiers to protect themselves from the hazardous environment. With respect to electric vehicles and their environmentally friendly features, Lin and Tan (2017) ask in a survey conducted in four Chinese cities how much participants are willing to pay more for the environmental benefit provided by electric vehicles. They find that the participants are willing to pay at least 30,600 CNY more for the environmental benefit of battery electric vehicles. In a similar survey, Lin and $\mathrm{Wu}$ (2018) show that the higher the concern about urban smog the higher is the willingness to purchase an electric vehicle. The previous empirical findings on the willingness to pay for a cleaner environment and to purchase electric vehicles to reduce pollution allows us to formulate the following hypothesis:

H4: Local air pollution has a positive effect on the diffusion of electric vehicles.

\section{Electric Vehicles and the Environment in China}

\subsection{Diffusion of Electric Vehicles in China}

According to estimates by the IEA (2019), China had the largest stock of electric cars, approximately 2.3 million $(1,760,000 \mathrm{BEV}$ and 540,000 PHEV) in 2018. China was the 


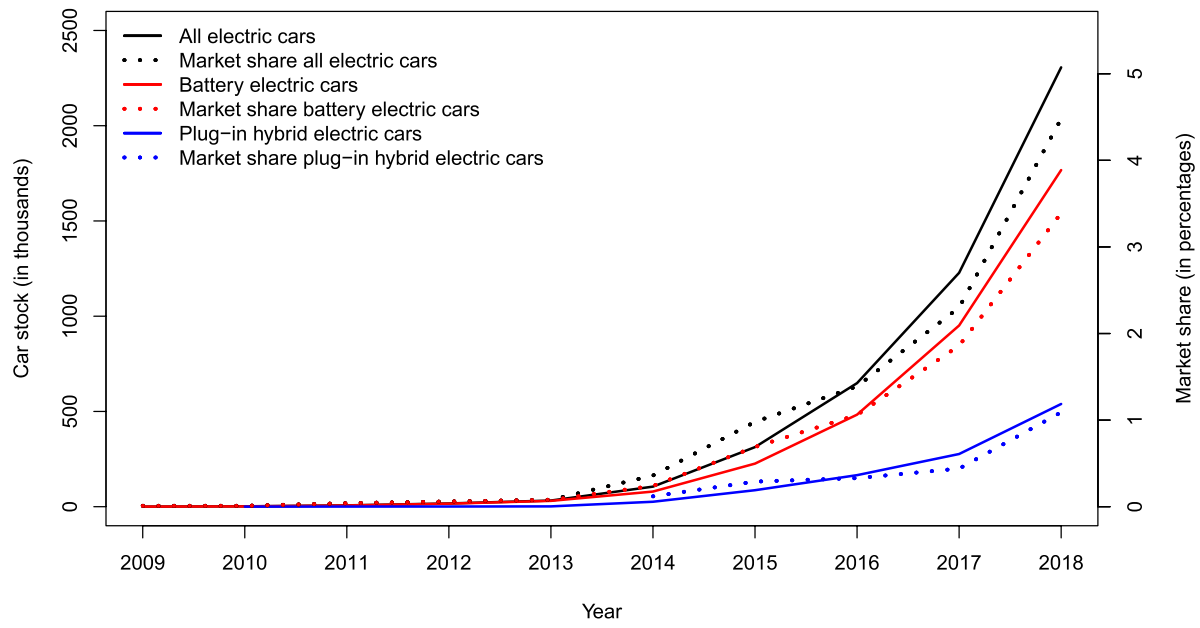

Fig. 1 Chinese electric car stock and share. Data source: IEA (2019)

largest market for electric cars with a global market share of $45 \%$ in 2018 . However, the share of new electric cars in China was still very low, with about $4.5 \%$ of all new registered cars in 2018. Figure 1 depicts the development of the BEV and PHEV car stock as well as market share over time. The exponential increase since 2013 is remarkable. The increase in market share indicates that substitution with conventional vehicles took place not solely in terms of an increase in absolute numbers of vehicles. A disaggregation at the regional level shows the concentration of electric vehicle diffusion to eastern China. The three regions with the highest number of electric vehicles were Beijing, Shanghai and Shenzhen, which together accounted for $37 \%$ of total electric vehicle sales in China. Customers of electric vehicles were until 2012 mainly governmental agencies or taxi companies, but since then, more and more private customers purchased electric vehicles (Yuan et al. 2015).

China was also the leader in terms of electric buses with more than 460,000 in operation in 2018 (IEA 2019). According to Shengyang (2018), in 2016 nearly $70 \%$ of all purchased buses in China were BEV and about $16 \%$ were PHEV buses. Buses were purchased by regional bus operators which are usually state owned but have to operate economically. Electric buses were mainly produced by two companies, BYD and Yutong. Similar to electric cars, most buses were operated in the eastern part of China. For example, Shenzhen was one of the pilot regions for electric vehicle diffusion and fostered an increase of electric vehicles between 2009 and 2017. By the end of 2017, Shenzhen managed to have an electric-only fleet of more than 16,000 buses (Dixon 2018). In addition, in other cities and regions, such as Beijing, Tianjin, Hebei, Guangzhou, or Xi' an the diffusion of electric buses increased substantially (IEA 2019).

Similar developments take place for charging infrastructure. IEA (2019) shows that China had about $45 \%$ of global public slow-charging infrastructure and more than three quarters of global public fast-charging infrastructure in $2018 .{ }^{3}$ Charging infrastructure can

\footnotetext{
${ }^{3}$ Besides public charging infrastructure, private home-charging infrastructure is of importance, but most households do not have their own parking space and lack this opportunity (Ou et al. 2018). However, the "Notice on Accelerating Residential EV Charging Infrastructure Construction" issued in 2016 provides a detailed plan for the installment of home-charging infrastructure.
} 
be distinguished into different types, serving different vehicle types or performing different services. Charging stations can serve many vehicles and different types at the same time. Charging points are usually used for electric cars, but also buses can be charged at such points. According to Ji and Huang (2018) in 2014, 780 centralized charging and battery swapping stations as well as 31,000 public charging points were in operation. The latter increased substantially in the following years to 450,000 private and public charging points by 2017. According to the "Guidelines for Accelerating the Plug-in Electric Vehicle Charging Infrastructure Deployment" issued in 2015, this number should increase to $4,800,000$ by the end of 2020 . In most cases, charging infrastructure were provided and operated by regional governments, since viable business models were not available (Ji and Huang 2018; Zhang et al. 2018).

\subsection{Electric Vehicle Policies in China}

The development and diffusion of electric vehicles in China were highly influenced and guided by policy on the national as well as the regional level. These policies target both the supply and the demand side in the innovation process and provide incentives and regulations for firms to produce electric vehicles as well as for customers to adopt them. ${ }^{4}$ Furthermore, several policies address the availability of charging infrastructure and provide nonpecuniary incentives. In the following, the main policies on the national as well as regional level are summarized. For detailed assessments see, among others, Yuan et al. (2015) who focus on industrial policies, Gong et al. (2013) who review major national policies, Zhang and Bai (2017) who review the national as well as selected regional policies, and Zhang et al. (2017) who focus on financial incentives.

The political support for electric vehicles in China on the national level began with the support of scientific and technological projects in the 8th Five-Year Plan for the period 1990-1995. Since then, the support for capacity building in this area has steadily increased and electric vehicles have been included in the "State High-Tech Development Plan (863 program)". The 11th Five-Year Plan (2006-2010) and the 12th Five-Year Plan (2011-2015) included strategic aims to develop an electric automobile industry with an emphasis on R\&D in the respective core technologies. The Five-Year Plans were complemented with several "Development Plans of Auto Industry", which contained detailed targets and strategies in developing the electric vehicle industry (see Yuan et al., 2015, for detailed discussions). The "Development plan for the new-energy automobile industry (2012-2020)" implemented in 2012 declares the transformation of the automobile industry and that BEVs will be the long-term strategic orientation in the future development of electric vehicles.

Besides these supply-side oriented policies, several demand-side instruments were implemented to support the diffusion of electric vehicles. In 2009, the "Notice on promotion and demonstration of energy-saving and new energy vehicles" was issued which included the "Ten Cities, Thousands of Vehicles" pilot program. The demonstration program provided subsidies for electric vehicle purchases in selected cities from 2009 to 2012. The program was extended in 2010 and 15 additional cities were included. The subsidies consisted of price deductions at the point of sale and were conditioned on the type of vehicle as well as on the battery capacity. The level of the subsidy and the conditions were

\footnotetext{
4 Policy learning plays a substantial role over time. Xu and $\mathrm{Su}$ (2016) show that policy targets changed over time from producer oriented to consumer oriented, increasing support for the diffusion of vehicles.
} 
augmented nearly each year (Yuan et al. 2015). Furthermore, the program contained an annual reduction of the subsidy level aiming to encourage innovative activity by car manufacturers and to create a self-sustainable market (Zhang and Bai 2017). The support was possible for both private as well as public actors; however, in some regions support was provided only for public actors. In the first years most vehicles were purchased by public actors (Yuan et al. 2015). In this period, the diffusion of electric vehicles was substantially below the governmental targets (Gong et al. 2013). Since 2013, the program has been succeeded by follow-up programs to guarantee continuous policy support and private actors have been incorporated in the scheme in all regions.

In 2013, the "Guiding Opinions on Accelerating the Promotion of the Application of New Energy Vehicles" provided further vehicle purchase subsidies and continued the "Ten Cities, Thousands of Vehicles" support for the period 2013-2015. Moreover, the policy reduced taxes, provided non-monetary incentives and revised fuel oil subsidies. In 2015, the "Notice concerning Financial Support Policy for Promotion and Application of New Energy Vehicle" continued the support for the period 2016 to 2020. Along these main policies, several other policies were implemented to increase the development of charging infrastructure, especially the "Guidelines for Accelerating the Plug-in Electric Vehicle Charging Infrastructure Deployment" in 2015 (Zhang and Bai 2017; Zhang et al. 2018). The support for electric vehicles was also implemented in the "Air Pollution Prevention and Control Action Plan" and public actors were encouraged to adopt electric vehicles.

Aside from the policies fostering the diffusion of electric vehicles on the national level, regional and city level policies play a major role. Zhang and Bai (2017) provide detailed assessments of policies in three regions and show the heterogeneity of policies and the degree of freedom possessed by regional authorities. Policy makers are motivated to account for their regional conditions in the support schemes. For example, Beijing and Shanghai have different subsidy schemes for BEVs and PHEVs. Shanghai promotes both BEVs and PHEVs with high subsidies, while Beijing only supports BEVs. To some extent, this difference can be attributed to regional protectionism because Beijing Automotive Industry Corporation (BAIC) - the regional company in Beijing - does not produce PHEVs (Wang et al. 2017b). These kinds of regional protectionism and favoritism are widespread (Gong et al. 2013). However, in nearly all regions and cities additional subsidies on top of national wide subsidies are granted. These subsidies differ between regions in terms of vehicles considered, granting conditions and changes over time.

Additionally, regions follow their own strategies to support and implement charging infrastructure and provide different tariffs for home-charging. Furthermore, some regions implement car-ownership policies to control congestion and pollution. License-plate lotteries or auctions to register new vehicles are used in several cities to control vehicle registration (see Chen and Zhao 2013, for details). In most of these cities, electric vehicles are exempt from these policies or a quota of license plates is available which allows electric car registration without uncertainty or waiting time. The implementation of license-plate lotteries can differ between BEVs and PHEVs. For example, in Beijing only BEVs, but not PHEVs, are exempt from the lotteries. The usually free license plate translates into considerable savings compared to a license plate for a conventional vehicle (Wang et al. 2017a). However, Wan et al. (2015) state that until 2014, the demand for these license plates was very low. Wang et al. (2017b), by contrast, argue that the exemptions from these lotteries should have major influence on electric vehicle diffusion. 


\subsection{Environmental Conditions in China}

The tremendous economic development in China generated several negative external effects, especially in terms of local and global pollution (He et al. 2002; Liu and Diamond 2005; Chan and Yao 2008). While emission of $\mathrm{CO}_{2}$ and other greenhouse gases have global, long term effects, the emission of other gases and particles have local effects, especially on people's health. With respect to local pollution, sulfur dioxide $\left(\mathrm{SO}_{2}\right)$, ground level ozone $\left(\mathrm{O}_{3}\right)$, nitrogen oxides $\left(\mathrm{NO}_{x}\right)$, and particulate matters with different aerodynamic diameters (esp. $\mathrm{PM}_{10}$ and $\mathrm{PM}_{2.5}$ ) are harmful. The concentration of these substances shows regional differences, with a higher intensity in the highly industrialized regions in the east (Liu et al. 2010). High concentration can lead to severe health effects and cause premature death (Matus et al. 2012; Lelieveld et al. 2015). For example, Rohde and Muller (2015) estimate that about $17 \%$ of all death in China can be attributed to local air pollution.

The reduction of local pollution levels is high on the Chinese government's agenda. Major emitters are the electricity and transportation sectors. Several policies were implemented over time to reduce local pollution, especially in the transportation sector (see Jin et al. 2016; Feng and Liao 2016, for reviews). Among them are restrictions on the use of cars, the retirement of old cars, fuel taxes and reduction of subsidies. Part of the efforts to reduce pollution from transportation includes the increase in the number of electric vehicles, which produce less or no tailpipe emissions (Zhang and Bai 2017). However, Huo et al. (2010, 2015) estimate that the current electricity mix fueling electric vehicles actually increases pollution, since electricity is generated mainly form coal. Only with a drastically changed fuel mix, which relies more on renewable energy, can electric vehicles contribute to a reduction in emissions. However, power plants are usually located outside of cities and pollution would shift from inside of cities to rural areas where less people would be exposed to the pollution.

\section{Empirical Analysis}

\subsection{Data}

The data used for the empirical analysis of the diffusion of electric vehicles covers the period from 2010 until 2016. We collect data for 31 Chinese regions (cities and provinces) (see Table 5 in the Appendix). The data is collected from various sources provided by the Chinese government. We group the data into dependent, explanatory, and control variables as well as variables to assess the robustness of our results. There is some missing data and we interpolate in most of the cases. In 2016, ten cities do not report vehicle registration data, so for these cities, we do not interpolate data. Descriptive statistics are provided in Table 1 and correlations in Table 6 in the Appendix.

\subsubsection{Regional Electric Vehicle Diffusion}

Similar to Wee et al. (2018) and Li et al. (2019) we measure the diffusion of electric vehicles by the annual new registered vehicles per region. We distinguish four different types of electric vehicles, based on the engine and vehicle type. With respect to the engine type, we 
Table 1 Descriptive statistics

\begin{tabular}{|c|c|c|c|c|c|c|c|}
\hline & Measurement & Min. & Mean & Median & Max. & S.D. & Obs. \\
\hline \multicolumn{8}{|l|}{ Dependent variables } \\
\hline New BEV Cars & Units & 0.00 & 898.67 & 0.00 & 52192.00 & 4018.79 & 207 \\
\hline New PHEV Cars & Units & 0.00 & 448.13 & 0.00 & 24707.00 & 2420.70 & 207 \\
\hline New BEV Buses & Units & 0.00 & 389.26 & 30.00 & 13139.00 & 1261.18 & 207 \\
\hline New PHEV Buses & Units & 0.00 & 117.99 & 0.00 & 1785.00 & 275.45 & 207 \\
\hline \multicolumn{8}{|c|}{ Explanatory variables } \\
\hline $\begin{array}{l}\text { Total Subsidy BEV } \\
\text { Cars }\end{array}$ & Thousand CNY & 0.00 & 51.56 & 65.25 & 125.40 & 42.40 & 217 \\
\hline $\begin{array}{l}\text { Total Subsidy } \\
\text { PHEV Cars }\end{array}$ & Thousand CNY & 0.00 & 36.59 & 40.00 & 100.00 & 30.69 & 217 \\
\hline $\begin{array}{l}\text { Total Subsidy BEV } \\
\text { Buses }\end{array}$ & Thousand CNY & 0.00 & 510.30 & 500.00 & 1100.00 & 259.20 & 217 \\
\hline $\begin{array}{l}\text { Total Subsidy } \\
\text { PHEV Buses }\end{array}$ & Thousand CNY & 0.00 & 330.43 & 360.00 & 725.00 & 152.14 & 217 \\
\hline $\begin{array}{l}\text { BEV Ownership } \\
\text { policy }\end{array}$ & Dummy & 0.00 & 0.08 & 0.00 & 1.00 & 0.27 & 217 \\
\hline $\begin{array}{l}\text { PHEV Ownership } \\
\text { Policy }\end{array}$ & Dummy & 0.00 & 0.09 & 0.00 & 1.00 & 0.29 & 217 \\
\hline $\begin{array}{l}\text { Charging Infrastruc- } \\
\text { ture }\end{array}$ & Cumulative units & 0.00 & 2238.44 & 227.00 & 68393.00 & 7038.53 & 217 \\
\hline $\mathrm{PM}_{10}$ Pollution & $\begin{array}{l}\text { Particle concentra- } \\
\text { tion }\end{array}$ & 19.30 & 90.78 & 89.00 & 192.00 & 30.67 & 217 \\
\hline \multicolumn{8}{|l|}{ Control variables } \\
\hline GDP & Thousand CNY & 15747.00 & 70314.29 & 67621.00 & 167411.00 & 31251.37 & 217 \\
\hline Population & Thousands & 57.43 & 17911.67 & 9204.00 & 74701.00 & 17973.39 & 217 \\
\hline Education & Relative measure & 0.31 & 4.09 & 2.57 & 14.62 & 3.37 & 217 \\
\hline \multicolumn{8}{|l|}{ Robustness variables } \\
\hline $\begin{array}{l}\text { Regional Subsidy } \\
\text { BEV Cars }\end{array}$ & Thousand CNY & 0.00 & 22.12 & 20.85 & 68.30 & 22.36 & 217 \\
\hline $\begin{array}{l}\text { Central Subsidy } \\
\text { BEV Cars }\end{array}$ & Thousand CNY & 0.00 & 29.44 & 41.70 & 60.00 & 23.00 & 217 \\
\hline $\begin{array}{l}\text { Regional Subsidy } \\
\text { PHEV Cars }\end{array}$ & Thousand CNY & 0.00 & 14.70 & 10.00 & 50.00 & 15.83 & 217 \\
\hline $\begin{array}{l}\text { Central Subsidy } \\
\text { PHEV Cars }\end{array}$ & Thousand CNY & 0.00 & 21.90 & 30.00 & 50.00 & 17.48 & 217 \\
\hline $\begin{array}{l}\text { Regional Subsidy } \\
\text { BEV Buses }\end{array}$ & Thousand CNY & 0.00 & 159.07 & 59.50 & 600.00 & 185.18 & 217 \\
\hline $\begin{array}{l}\text { Central Subsidy } \\
\text { BEV Buses }\end{array}$ & Thousand CNY & 0.00 & 351.24 & 380.00 & 500.00 & 157.96 & 217 \\
\hline $\begin{array}{l}\text { Regional Subsidy } \\
\text { PHEV Buses }\end{array}$ & Thousand CNY & 0.00 & 85.90 & 0.00 & 500.00 & 109.45 & 217 \\
\hline $\begin{array}{l}\text { Central Subsidy } \\
\text { PHEV Buses }\end{array}$ & Thousand CNY & 0.00 & 244.53 & 237.50 & 360.00 & 109.32 & 217 \\
\hline Charging Stations & Cumulative units & 0.00 & 39.00 & 5.00 & 612.00 & 96.42 & 217 \\
\hline Charging Points & Cumulative units & 0.00 & 2163.12 & 220.00 & 67781.00 & 6962.23 & 217 \\
\hline Air Quality Index & Share of good days & 29.00 & 77.77 & 83.56 & 100.00 & 17.92 & 217 \\
\hline
\end{tabular}

Note: Variables are presented in its original form, but enter the regressions log-transformed 
distinguish between Battery Electric Vehicles (BEV), which are powered solely by electricity, and Plug-in Hybrid Electric Vehicles (PHEV), which have both a small battery to run an electric engine as well as an internal combustion engine that can be used if the battery is empty. These two are the most frequently used engine types and can be used in cars for individual transport as well as in buses for public transport. These four types of vehicles, BEV cars, PHEV cars, BEV buses, and PHEV buses, are the four dependent variables reflecting the diffusion of electric vehicles in our analysis. We collect the annual registered vehicles from the Yearbook of Energy-Saving and New Energy Vehicles in China, (20112017). We log-transform the data to account for the increasing trend over time.

\subsubsection{Purchasing Subsidies}

Purchasing subsidies for electric vehicles are different among the four different vehicle types, since the subsidy amount depends on both the kind of vehicle and vehicle characteristics. The overall subsidy amount for each vehicle type consists of central government level and region government level subsidies. ${ }^{5}$ As discussed in Sect. 3.2 the national policy "Ten Cities, Thousands of Vehicles" program and its successors granted subsidies for purchases in selected region (see Table 5 in the Appendix when a region was covered by the programs). Regional authorities complemented the subsidies with their own subsidy scheme or implemented subsidies independent of central government polices. Subsidies are conditioned on the capacity of batteries for all vehicle types and the size of the buses. Gong et al. (2013) provide a detailed description of the factors determining the subsidy amount. We collect the central and regional government subsidy amount from the Yearbook of Energy-Saving and New Energy Vehicles in China, (2011-2017). To quantify the central and the regional subsidy amounts, we take the average subsidy amount for a vehicle type each. ${ }^{6}$ We use the total subsidy amount as our main variable of interest, since customers make decisions based on the overall subsidy they receive. We use the separation of central subsidy amount and regional subsidy amounts as a robustness test, where we have to be aware of a considerable correlation between the two. All values are measured in thousand CNY and log-transformed.

\subsubsection{Non-Monetary Incentives}

To account for non-monetary incentives, we collect car-ownership policies at the regional level. Two kinds of ownership policies are implemented, namely license-plate lotteries and license-plate auctions. Both policies restrict the registration of cars with internal combustion engine but exempt electric vehicles from this restriction. These policies are implemented in six regions in our sample and at different points in time (Wang et al. 2017a). They apply only to cars and not to buses. The regions in our sample which implemented such a policy are Beijing, Guangzhou, Hangzhou, Shanghai, Shenzhen, and Tianjin (see Table 5 for details). Since Beijing implemented the license-plate lottery exemption only for

\footnotetext{
5 The subsidies are regionally bound to the purchaser's residence. Usually, purchasers have to buy and register their vehicle in the region of their residence and benefiting from subsidies in other regions should not be possible.

6 For example, the national subsidy for BEV buses is 300, 400 or 500 thousand CNY/vehicle depending on the length of the bus. We calculate the average amount of subsidy which is 400 thousand CNY/vehicle. We proceed similarly for regional subsidies.
} 
BEV cars, variables are generated for BEV and PHEV cars separately. The policy is operationalized as a dummy variable for the region and year it is active.

\subsubsection{Public Charging Infrastructure}

We collect the cumulative number of public charging opportunities from the Yearbook of Energy-Saving and New Energy Vehicles in China, (2011-2017). The measure counts the presence of public charging facilities, consisting of charging points and charging stations, but it does not take into account how many vehicles can charge simultaneously at a location or the speed of charging. ${ }^{7}$ Normally, charging points allow only for slow charging and are located in parking spots or on the roadside, while charging stations are usually located close to urban roads or highways and serve a large number of vehicles, especially buses. Charging stations require larger space and are more expensive but they offer different charging opportunities, such as fast charging or battery swapping (Zheng et al. 2012; Ji and Huang 2018). The overall number of charging possibilities is suitable to measure how the perceived availability of public charging infrastructure can influence the diffusion. For a robustness test, we separate the charging infrastructure into charging points and charging stations. We assume that charging points are primarily relevant for cars, while charging stations are primarily relevant for buses. We log-transform the cumulative data.

\subsubsection{Local Air Pollution Measures}

We account for the local air pollution via two different measures. Unfortunately, both are imperfect because of data constraints. The data is taken from the Environment Bulletin of Chinese Regions, (2011-2017). The first measure is the $\mathrm{PM}_{10}$ particle concentration, which is measured on a daily basis and averaged per year. While most of the $\mathrm{PM}_{10}$ pollution is emitted by the transportation sector, this measure captures only a part of the overall pollution. The second measure is the Air Quality Index, which is as a composite indicator of several pollutants $\left(\mathrm{SO}_{2}, \mathrm{NO}_{2}, \mathrm{O}_{3}, \mathrm{CO}, \mathrm{PM}_{10}\right.$ and $\left.\mathrm{PM}_{2.5}\right)$. It is measured by the share of days with air quality equal to or above Grade II (good days). The advantages of using this measure are that it captures more pollutants and that it does not need any yearly aggregation. Unfortunately, the composition of Air Quality Index and its measurement changed in 2013, which reduces its reliability and comparability over time. Furthermore, we have to treat the environmental data with caution, since it is sensitive to political interests and the measurement could be adjusted in favor of better reporting. Chen et al. (2012) find evidence of manipulation of Air Quality Index data between 2000-2009 by regional governments, who were motivated to achieve a reward. Similarly, Ghanem and Zhang (2014) find in daily data for the period from 2001 until 2010 anomalies in reported $\mathrm{PM}_{10}$ pollution levels from about $50 \%$ of the cities. Even though these manipulations seem severe, Chen et al. (2012) nevertheless conclude that the environmental data is useful, since it still correlates well with other environmental data from external sources. We use the $\mathrm{PM}_{10}$ pollution as our preferred measure due to its measurement consistency over time and we use the Air Quality Index for a robustness test. The two measures should be negatively correlated.

\footnotetext{
7 The data does not contain home-charging possibilities. However, Ou et al. (2018) shows that home-charging was very limited in the time period considered because most households do not have their own parking space.
} 


\subsubsection{Control Variables}

Three control variables are used to account for the overall regional differences and development as are other potentially relevant regional factors. ${ }^{8}$ In line with previous studies (e.g. Egnér and Trosvik 2018; Wee et al. 2018), we collect regional GDP and population data to account for economic development, market size, and other regional differences from the Statistical Yearbook of Chinese Regions, (2011-2017). Carley et al. (2013) and Hackbarth and Madlener (2013) show that more highly educated people have a higher intent to purchase electric vehicles. Furthermore, a higher education level can be associated with a greater environmental awareness, which can increase electric vehicle adoption (Lin and Tan 2017). To account for the education level in a region, we build an indicator which calculates participants in regular higher education institutions as a share of total resident population of a region. The data is collected from the Statistical Yearbook of Chinese Regions, (2011-2017). All measures are log-transformed.

\subsection{Econometric Approach}

Because diffusion is a dynamic process that is influenced by past diffusion and feedback effects (e.g. Hall 2006), our estimation strategy relies on Generalized Method of Moments (GMM) dynamic panel estimations to not only account for such dynamics but to also account for the endogeneity of policy interventions. The dynamic panel approach allows for a consideration of the whole history of the diffusion process (Greene 2012). We use the system GMM approach proposed by Arellano and Bover (1995), Blundell and Bond (1998), Bond (2002), which simultaneously uses the level as well as first difference to yield additional internal instruments. The system GMM is also more reliable in small samples (Soto 2009). We use the two-step approach to account for heteroskedasticity in our data and we calculate robust standard errors using the Windmeijer (2005) correction. We report the squared correlation between the predicted vehicle diffusion and the actual vehicle diffusion as a goodness-of-fit measure (Windmeijer 1995).

For the instrumentation, we use all available lags of our lagged dependent variable. However, we restrict the number of further instruments to avoid overidentification and inflation of the Hansen J-test (Roodman 2009). We use the first four lags of our variables of interest, because we assume that they could be pre-determined due to potential influence by previous electric vehicle registrations. The control variables enter the set of instruments with no lag, since they are exogenous. We collapse the instruments, which is recommended

\footnotetext{
${ }^{8}$ Further control variables are suggested in the literature. Fuel and electricity prices, in particular, show potential relevance to induce diffusion. In China, fuel and electricity prices are not determined on markets; rather, the central and regional governments set them based on the regional economic developments. Therefore, these prices are highly correlated with regional GDP and we abstain from using them in our analysis. However, neglecting them is not detrimental, since their empirical relevance is weak or inconclusive. In cross-country settings, both prices show no effect (e.g. Sierzchula et al. 2014; Münzel et al. 2019) and for the US, Clinton and Steinberg (2019) find no effects and Wee et al. (2018) find mixed results. Another factor which can influence the diffusion of electric vehicles is the diffusion of conventional vehicles. Unfortunately, there is no data of new conventional vehicle registrations available at the regional level. We collected data on the overall number of vehicles registered in a region, but these figures do not account for scrapping vehicles. Manual inspection sheds serious doubts on the data quality. We used the overall number of vehicles registered in a region as an additional control variable, but it does not affect diffusion and we abstain from including it in the analysis.
} 
for small samples. We test for overidentifying restrictions using the Hansen J-test (Hansen 1982 ) and report $p$-values as well as the test's degrees of freedom. We also report the $p$-values for the second order autocorrelation test (m2-Test) (Arellano and Bond 1991).

We estimate regressions for the different vehicle types $V=\{B E V$ cars, PHEV cars, BEV buses, PHEV buses $\}$ each, with $V$ as an index for vehicle specific variables for region $i$ and year $t$ :

$$
\begin{aligned}
\text { New }_{\text {Vehicle }} \text { Vit }_{1}= & \alpha \text { New } \text { Vehicle }_{\text {Vi,t }-1}+\beta_{1} \text { Total Subsidy }_{\text {Vit }} \\
& +\beta_{2} \text { Ownership Policy }_{\text {Vit }}+\beta_{3} \text { Charging Infrastructure }_{i t} \\
& +\beta_{4} \text { PM }_{10} \text { Pollution }_{i t}+\beta \text { Controls }_{i t}+\mu_{i}+\epsilon_{i t}
\end{aligned}
$$

with New Vehicle $_{V i t}$ as the annual newly registered vehicles, Total Subsidy ${ }_{V i t}$ the vehicle specific subsidies, Ownership Policy ${ }_{V i t}$ the vehicle specific non-monetary incentives, Charging Infrastructure ${ }_{i t}$ as the accumulated number of charging places and PM $_{10}$ Pollution $_{i t}$ as one of the measures for local environmental pollution. Controls ${ }_{i t}$ is the vector of control variables. $\mu_{i}$ are region specific fixed effects and $\epsilon_{i t}$ is an error term.

We estimate five different models for each vehicle type $V$ (Model a-d) where we stepwise include the variables of interest. Model 1 is the baseline model, which includes the lagged dependent variable and the control variables. Model 2 adds the vehicle specific total subsidies, which are proposed in hypothesis 1 . Model 3 adds the vehicle specific ownership policies, which are the non-monetary incentives proposed in hypothesis 2 . This policy applies only to cars and is therefore only present for BEV cars and PHEV cars. Model 4 adds the charging infrastructure proposed in hypothesis 3 . Model 5 adds the local environmental pollution in terms of $\mathrm{PM}_{10}$ particles and is proposed in hypothesis 4 . Model 5 is the full model as presented above.

As robustness tests, we report estimates for three additional models in which we exchange variables from Model 5. In Model 6, the variable total subsidy is differentiated into the subsidies provided by the regional and those provided by the central governments. In Model 7, charging infrastructure is exchanged for vehicle-specific charging infrastructure, charging points are used in the regressions for cars and charging stations in the regressions for buses. In Model 8, we use an alternative measure for local air pollution, the Air Quality Index. We conduct several additional robustness tests, which are available in the online supplementary material.

\subsection{Results}

Tables 2 and 3 provide the regression results for the BEV and PHEV cars and BEV and PHEV buses respectively. Table 4 provides robustness tests for all vehicle types. The goodness of fit - the squared correlation of the annual vehicle diffusion and the fitted values-is the highest for BEV cars and the lowest for PHEV buses. The goodness of fit is in general quite good and usually increases with additional variables. The Hansen J-test indicates for most models that the instrumentation is not weak, only Models 1a,c, d and Model 2d suffer from weak instrumentation. Overall, the test statistics improve with an increase in variables in the regression. Serial autocorrelation seems to be partly a problem in the BEV car regressions, since the m2-Test cannot be rejected in all cases. ${ }^{9}$ With respect to the

\footnotetext{
9 We conducted an additional robustness test and additionally included the dependent variable with lag 2 . For BEV cars, this variable was negative significant in most specifications with a significant coefficient of about -0.2 . The other co-variates changed only marginally. In the estimations for the other vehicle types, the
} 


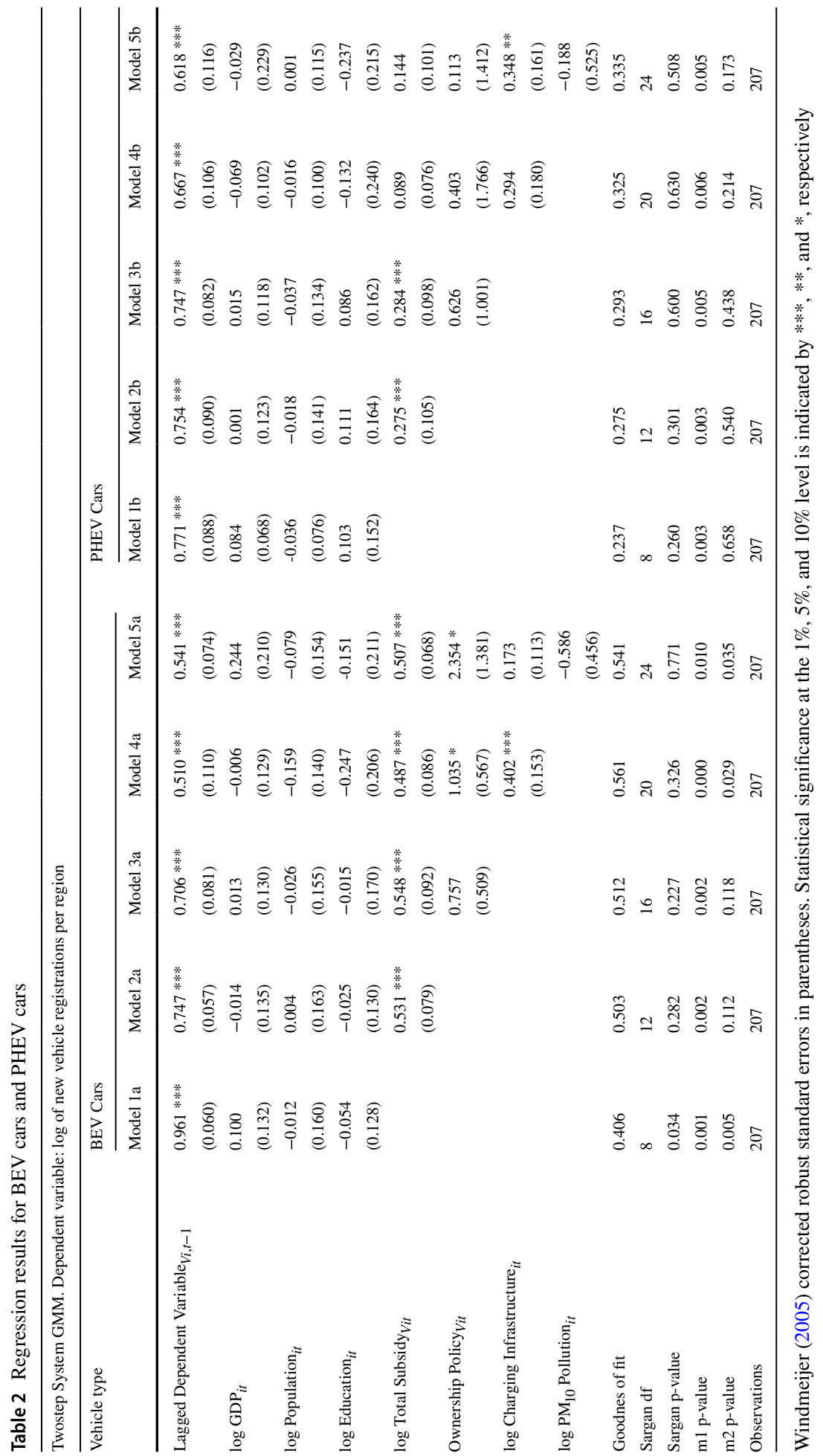




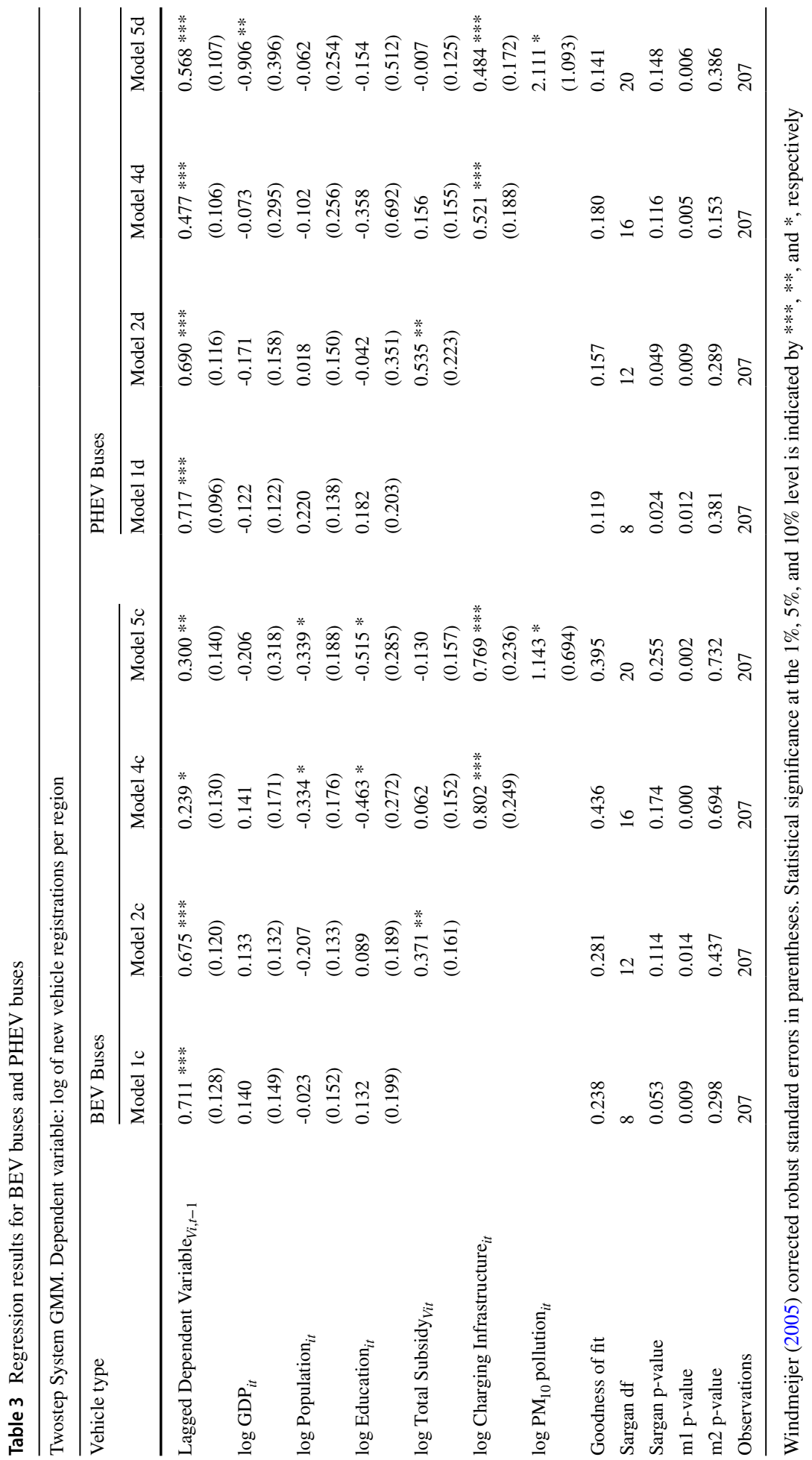




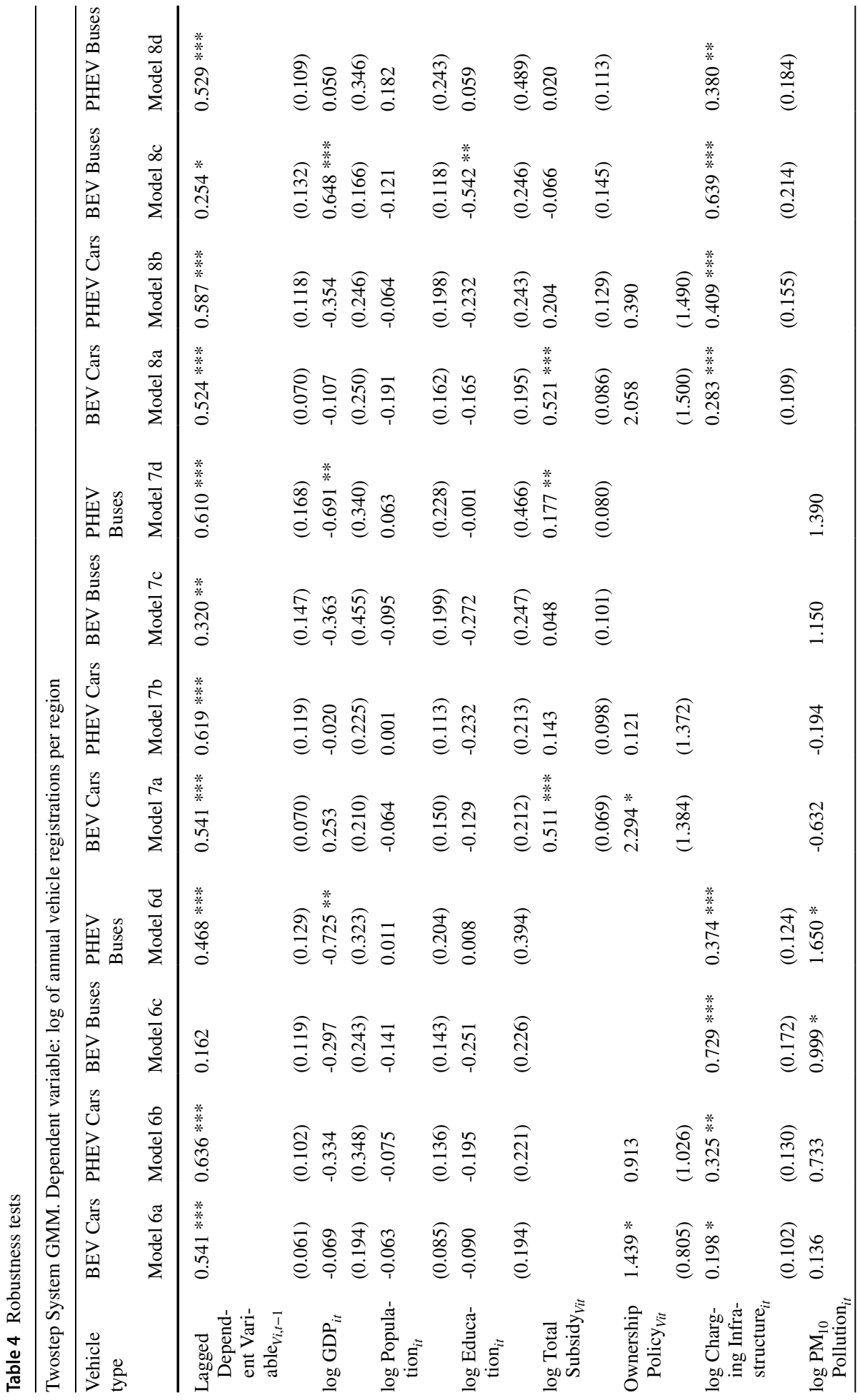




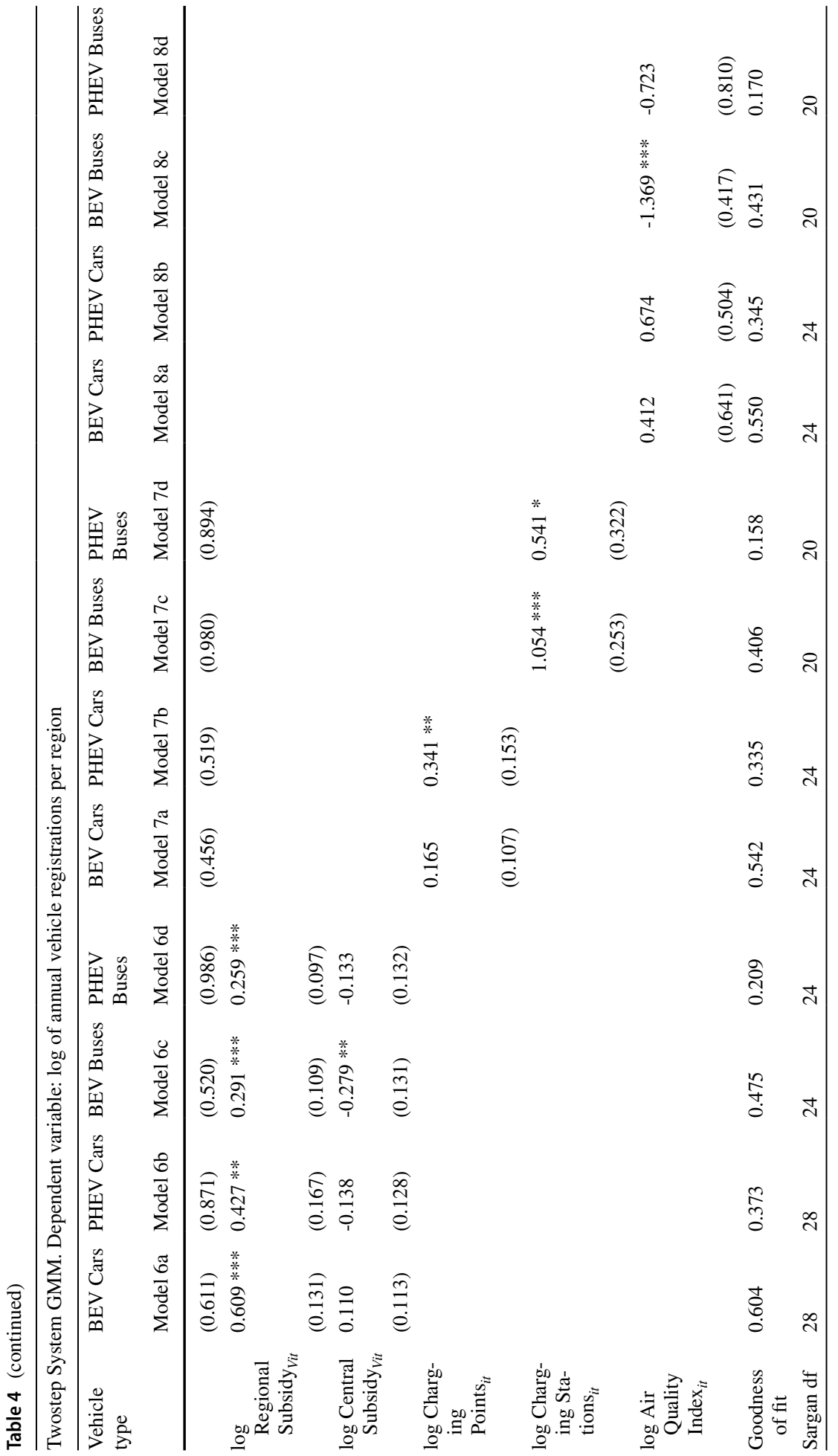




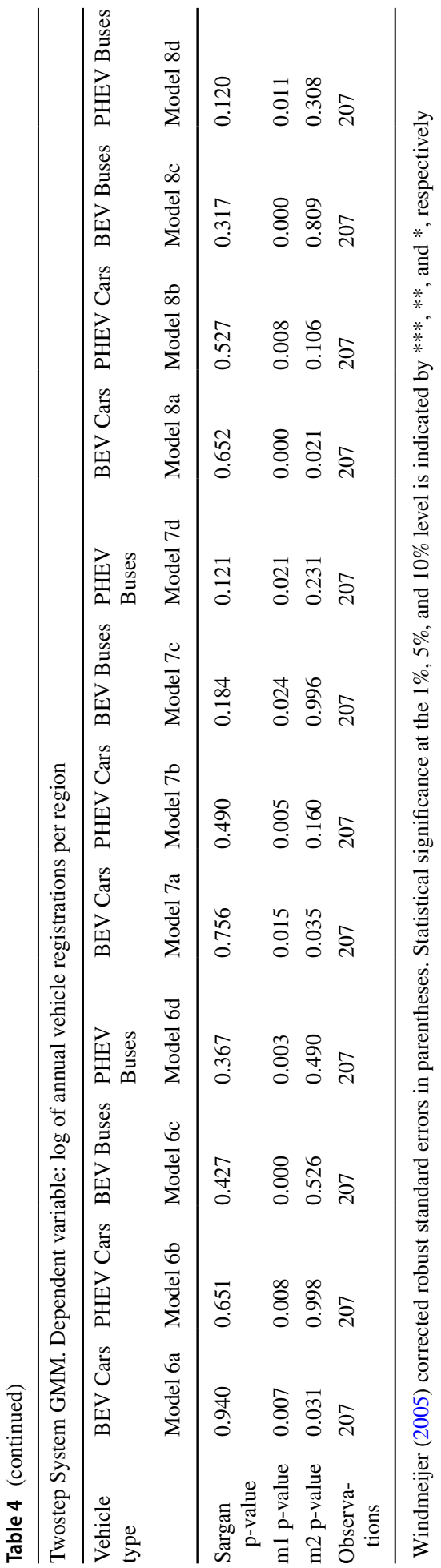


estimation results, in nearly all models a strong effect of the lag dependent variable is present, indicating the high relevance of previous diffusion for current diffusion. ${ }^{10}$ The coefficient size of the lagged dependent variable decreases with the inclusion of additional variables and ranges between 0.3 and 0.6 in the full specifications in Model 5. The dynamic nature of the diffusion process could be related to the increased visibility and availability of electric vehicles but also could be due to cost reductions based on learning curves which may be affected by past influences. In general, the three control variables show no effect on the diffusion irrespective of vehicle type. In the following, we discuss the results regarding the different hypotheses derived in Sect. 2.

\subsubsection{Financial Purchase Incentives}

The total subsidy to purchase electric vehicles reflects vehicle type dependent effects. A robust positive significant effect of total subsidy is only present for BEV cars. The effect size can be interpreted as an elasticity, where a one percent increase in total subsidy translates to an increase of newly registered BEV cars of about 0.5 percent. ${ }^{11}$ This effect for $\mathrm{BEV}$ cars is plausible, since the total subsidy is quite high and it covers the price difference between the internal combustion engine cars, providing a sufficient high incentive. For PHEV cars, there is a significant effect in Models $2 \mathrm{~b}$ and $3 \mathrm{~b}$ which translates to an elasticity of about 0.28 . However, the significant effect becomes insignificant with the inclusion of charging infrastructure in Model 4b. This co-variate dependent effect is puzzling but could be explained by a government reaction with a simultaneous change in subsidy and infrastructure support. A similar pattern for buses as for PHEV cars is present. For BEV buses Model 2c and for PHEV buses Model 2d show significant effects for total subsidy of about 0.37 and 0.54 , respectively, but with the inclusion of further co-variates, the effects disappear. $^{12}$

The robustness test, in which the total subsidy is separated into regional and central subsidies, reveals that the subsidies provided by the regional governments are decisive. For all vehicle types (Models 6a-d), the regional subsidies have a significant positive coefficient, which are for cars larger than the total subsidy coefficients. The effects for buses are smaller than the ones in Models $2 \mathrm{c}$ and $2 \mathrm{~d}$ and are about 0.29 and 0.26 respectively. The central government subsidies are not significant except for BEV buses, where they have a negative significant coefficient. The overall missing or negative effect of central governmental subsidies is surprising but most likely related to the fact that the central government subsidies decrease over time, while at the same time annual vehicle registrations increase. Furthermore, there is not much regional variation in the central government subsidy, since it discriminates only between regions that receive a subsidy and those that do not. Overall,

Footnote 9 (continued)

additional lagged dependent variable was usually not significant and co-variates changed only marginally. Results are available in Table $\mathrm{O} 1$ in the online supplementary material.

10 To assure the reliability of our estimation approach, we compared it to dynamic panel fixed-effects specification with a lagged dependent variable. Since the fixed-effects specification should be biased downwards, the coefficient for the lagged dependent variable should be smaller than the ones from the GMM estimations. This is the case for all our models which gives us confidence that the GMM specification is sound. Results are available in Table $\mathrm{O} 2$ in the online supplementary material.

11 The effect sizes should be interpreted with care and more like an upper bound than an average effect, since the data can be adjusted by the regional governments to meet car registration targets and requirements. 12 We estimate an alternative specification in which we do not log-transform the subsidy data and coefficients can be interpreted as semi-elasticities. The results do not change qualitatively but have smaller standard errors. Results are available in Table $\mathrm{O} 3$ in the online supplementary material. 
the robustness test provides confidence that subsidies increase diffusion for electric vehicles, but the decreasing central government subsidy seems to dilute the overall effect.

\subsubsection{Regulatory Incentives}

Car ownership policies, which are implemented in several regions to control the number of cars, show significant coefficients only for BEV cars but not for PHEV cars. For BEV cars, the significance of the coefficient is sensitive to the inclusion of co-variates. While the coefficient is statistically insignificant in Model 3a ( $p$-value $=0.13)$, including charging infrastructure in Model 4a renders the coefficient significant, thereby the coefficient size varies considerably between the model specifications and the effect is in not very precise. The coefficient size also varies in this range in the different robustness specifications in Models 6a, 7a and 8a. Considering the effect size based on the two significant coefficients in Model 4a and 5a, implementing ownership policies translates to an increase of newly registered BEV cars between about $182 \%$ and $953 \%$ compared to regions without ownership policies. Since the six regions with BEV car ownership policies account for more than $50 \%$ of the registered vehicle in our sample, the effect size is reasonable. The substantial range of estimates stems from the imprecise measurement via a dummy variable and does not measure the shadow price of the incentive, but qualitative discussions of these policies attribute substantial relevance to them (e.g. Wang et al. 2017b; Li et al. 2019). Overall, the hypothesis that non-monetary incentives increase diffusion is supported only in regards to BEV cars.

\subsubsection{Public Charging Infrastructure}

The third hypothesis states that the presence of public charging infrastructure has a positive effect on the diffusion of electric vehicles. In general, this hypothesis is supported by the results; however, the effect is not always robust for cars and fluctuates with the inclusion of some covariates. For BEV cars, the coefficient for charging infrastructure is significant in Model 4a but not if the $\mathrm{PM}_{10}$ pollution is included in Model 5a. The $\mathrm{PM}_{10}$ pollution measure seems to distort the estimation: in Model 8a where the Air Quality Index is used instead, the coefficient for charging infrastructure is significant. For PHEV cars, the coefficient is barely insignificant in Model $4 \mathrm{~b}(p$-value $=0.103)$ but becomes significant with the inclusion of the $\mathrm{PM}_{10}$ pollution in Model 5b. Furthermore, in the robustness Models 6a, $8 \mathrm{a}$, as well as Models $6 \mathrm{~b}$ and $8 \mathrm{~b}$ the coefficients are significant as well. The effect sizes for BEV cars range between 0.2 and 0.4 and for PHEV cars between about 0.3 and 0.4. The results for the BEV and PHEV buses show significant positive coefficients, which are robust across all specifications. For both bus types, the elasticity is larger compared to cars - for BEV buses between 0.6 and 0.8 and for PHEV buses between 0.4 and 0.5.

We perform a robustness test in which the charging infrastructure is separated in charging points and charging stations. The intuition is that charging points are more relevant for cars while buses should be more dependent on charging stations. Regional policy makers could use this dependency to target the diffusion of either cars or buses by higher support for specific infrastructure. We estimate in Models 7a,b the effect of charging points on both car types and in Models 7c,d the effect of charging stations on both bus types. In the case of BEV cars, there is no significant effect for charging points in Model $7 \mathrm{a} .{ }^{13}$ For

13 We estimated Model 7a with the Air Quality Index as an alternative pollution measure and charging points have an effect size of 0.272 and is significant at the $1 \%$ level, again showing disturbances of the $\mathrm{PM}_{10}$ 
PHEV cars, there is a significant effect of charging points, which is of similar size as charging infrastructure in general. For buses, there is a significant effect of charging stations for both bus types. In particular, the coefficient of BEV buses is considerably larger than of general charging infrastructure, with an effect of approximately 1.05. This result is reasonable since buses hardly charge at charging points; instead, they usually charge in larger facilities.

\subsubsection{Regional Air Pollution}

The fourth hypothesis postulates a relationship between the local environmental condition and the diffusion of electric vehicles. Such a relationship seems not to exist for electric cars, as none of our $\mathrm{PM}_{10}$ pollution estimates is significant for BEV or PHEV cars. For buses, large but weakly significant coefficients exist for $\mathrm{PM}_{10}$ pollution in Models $5 \mathrm{c}$ and $5 \mathrm{~d}$ but also in Models $6 \mathrm{c}$ and $6 \mathrm{~d}$. For BEV buses, the effect size is between 1.0 and 1.1 but for PHEV buses it is considerably larger, between 1.7 and 2.1. Interestingly, in Models $7 \mathrm{c}$ and $7 \mathrm{~d}$ the measure for charging stations renders the coefficients for $\mathrm{PM}_{10}$ pollution for both bus types insignificant, indicating that there is a relationship between pollution and a policy response to it. ${ }^{14}$ However, $\mathrm{PM}_{10}$ pollution seems to be a poor measure, as indicated by the decrease of the goodness of fit in all models with its inclusion. This poor measurement quality could be related to the ease with which the regional governments in favor of meeting policy targets could adjust the measurement.

As a robustness test, we use the Air Quality Index as an alternative measure of pollution. This composite index counts the number of good days in a region and a decrease in good days should result in higher diffusion. This pollution measure again shows in Model $8 \mathrm{a}$ and $8 \mathrm{~b}$ no effect for electric cars. Furthermore, it confirms the finding for BEV buses, where we see a large and significant effect size of about -1.4. For PHEV buses, the effect is not significant. Overall, these findings provide confidence that local air pollution can influence the diffusion of electric vehicles, but only for buses. The effects for buses are quite reasonable, since regional governments can use buses to address local air pollution while car owners might not want to contribute to the public good.

\section{Discussion and Conclusion}

Electric vehicles are perceived as a possible means to reduce local and global harmful emissions. However, electric vehicle diffusion is impeded by multiple externalities (Rennings 2000; Jaffe et al. 2005). Governments intervene and implement policies to support the diffusion of electric vehicles. We empirically analyze the factors that determine the

\footnotetext{
Footnote 13 (continued)

pollution measure for BEV car specifications. Results are available in Table O4 in the online supplementary material.

14 We conducted an additional robustness test and excluded the two regions with the highest annual diffusion of BEV buses (Shenzhen and Hebei) and PHEV buses (Guangzhou and Hunan), since regional governments could use buses as means to address pollution. In these Models, only the effect of $\mathrm{PM}_{10}$ pollution for $\mathrm{BEV}$ buses is no longer significant whereas all other estimates remain qualitatively the same. Since Hebei has the highest level of $\mathrm{PM}_{10}$ pollution in the sample, $\mathrm{PM}_{10}$ pollution results for $\mathrm{BEV}$ buses seems to be driven by the highest polluting regions and adopting electric buses seem to be a policy response. Results are available in Table O5 in the online supplementary material.
} 
diffusion of electric vehicles in China for a panel of 31 Chinese regions for the period 2010-2016. We separately analyze the diffusion of Battery Electric (BEV) cars and Plug-in Hybrid Electric (PHEV) cars as well as Battery Electric (BEV) buses and Plug-in Hybrid Electric (PHEV) buses. We derived four hypotheses which postulate that monetary and non-monetary policy interventions, public charging infrastructure as well as the local environmental conditions influence the diffusion of electric vehicles. Our results add further insights to the literature on the diffusion of environmentally friendly technologies in general and of electric vehicles and especially electric buses in particular.

The results of our dynamic panel system GMM estimations show that the diffusion process is highly dynamic and that diffusion is substantially driven by past diffusion. This result is consistent with Qiu et al. (2019), who find similar coefficient sizes in a monthly panel for Chinese cities and congruent with Jenn et al. (2013) and Jenn et al. (2018), who find even larger effect sizes for the lagged dependent variables in estimations for US regions. Via the lagged dependent variable, the estimation accounts for the entire history of the diffusion process and can reveal benefits from adoption, exert neighborhood effects, reduce information problems, or reduce uncertainty, all of which can increase diffusion (cf. Hall 2006; Coffman et al. 2016). In addition, cost reductions from knowledge accumulation and scale effects can be captured by the past diffusion (Weiss et al. 2012).

With respect to the governmental monetary subsidies, our results show that they increase diffusion, especially for BEV cars. These finding are in line with previous literature, which finds similar effects for BEV cars diffusion in general (see for a review of the literature Hardman et al. 2017), and particular in China (Ma et al. 2017). While our results are very robust for BEV cars, with an elasticity of about 0.5 , for the other vehicle types, the results are sensitive to co-variates. In addition, for PHEV vehicles the elasticities are substantially smaller. In a more detailed assessment, we separate the total subsidies into regional and central government subsidies. The results reveal that subsidies provided by the regional governments have a significant positive effect on diffusion for all vehicle types, but the central government subsidies via the "Ten Cities, Thousands of Vehicles" program and its successors show either no significant effects or, in the case of BEV buses, they show a negative significant effect. Since the central government program has a subsidy degression over time, the overall effect seems to be diminished and the anticipated vehicle cost reductions could most likely not compensate for the subsidy reductions (Zhang and Bai 2017). While these results are in line with the existing literature that purchasing subsidies is effective, the results do not provide information about its efficiency. Sheldon and Dua (2020) show that the subsidy efficiency in China could be improved and diffusion could be increased if high-income households were not eligible for the subsidy and if lower-income households were more supported. Furthermore, most BEV and PHEV buses are operated by governmental agencies or firms contracted by the government. Therefore, monetary concerns could be secondary for the purchasing decision of electric buses-as indicated by the smaller elasticities compared to cars-but the political will to implement electric buses remains important (Dixon 2018). ${ }^{15}$

\footnotetext{
15 Accounting for the influence of policy is difficult in our setting. We collected data on the ownership of bus operators and separated them into governmentally owned and privately owned. Because the data is time-invariant and cannot be used in the GMM estimation, cross-sectional regressions were used but differences in bus operators do not influence diffusion. Furthermore, we collected information on the regional implementation of emission trading systems (Goulder et al. 2017), but again-time and regional variation is very low in our sample and cross-sectional regressions do not show a correlation.
} 
Non-monetary regulatory incentives, such as the exemptions from license-plate lotteries or auctions for cars examined in this study, influences the diffusion of BEV cars but not of PHEV cars. Previous studies attribute large incentives to these instruments in China, as the exemption from purchasing a license-plate for a conventional car brings large savings (e.g. Wang et al. 2017b; Li et al. 2019). The effect size of introducing an exemption from license-plate lotteries or auctions for BEV cars are substantial. The six cities that have implemented such policies account for more than 50\% of BEV car registrations in our sample. In a survey of customers and potential customers across China, Ouyang et al. (2020) show that the exception from license-plate restrictions has the highest influence of purchasing decisions. However, contrary to the claim by Wang et al. (2017b) that these exemptions should be decisive for the diffusion of PHEV cars as well, we find no effect in our econometric approach for this car type. Wan et al. (2015) points out that in the first years after implementation, there was little demand for the free license plates. This lack of utilization could explain the non-significant effect for PHEV cars and potentially indicate that the relevance of this instrument is still unfolding.

Our results show that public charging infrastructure is relevant for all vehicle types, which is in line with most previous research (e.g. Sierzchula et al. 2014; Coffman et al. 2016; Wang et al. 2017a; Egnér and Trosvik 2018). Concerns about endogeneity should be ruled out by the GMM estimation (Coffman et al. 2016; Egnér and Trosvik 2018). In our analysis, we provide a more detailed assessment of charging infrastructure and show that different kinds of charging infrastructure matter for different vehicle types. Charging stations are especially relevant for buses, whereas car diffusion is more affected by charging points. Concerning the effect sizes, the elasticity for charging infrastructure ranges between 0.2 and 0.4 for cars and between 0.4 and 0.8 for buses. The BEV car elasticities for charging infrastructure are consistent with the results from Egnér and Trosvik (2018), who estimate for Swedish regions an elasticity between 0.2 and 0.7 , depending of model specification and for a slightly different operationalization. Li et al. (2017) find larger elasticities of about 0.8 for electric cars in the US but account for feedback effects from increases in charging infrastructure due to diffusion. The results for cars are also compelling in light of studies which see range anxiety as a large obstacle for customers' adoption decisions (Egbue and Long 2012). The presence of sufficient charging infrastructure can consequently reduce this anxiety and increase diffusion. While our study supports the relevance of public charging infrastructure for vehicle diffusion, it does not answer how much or which kind of charging infrastructure is necessary (Hardman et al. 2018; Funke et al. 2019). Nevertheless, the diffusion of charging infrastructure and vehicles is co-evolving and charging opportunities need to increase further to serve additional customers to keep up the effect. The ambitious plans of the Chinese government in the "Guidelines for Accelerating the Plug-in Electric Vehicle Charging Infrastructure Deployment" should reduce any potential bottleneck if implemented accordingly (Ji and Huang 2018) and can be seen as an approach by the Chinese government to provide charging infrastructure as a public good.

With respect to the effect of local environmental conditions on diffusion, we are, to our knowledge, the first to test this relationship empirically. Simulation studies on the diffusion of environmentally friendly technologies as well as empirical studies on the willingness to pay for a clean environment suggest such a relationship (Cantono and Silverberg 2009; Lin and Tan 2017; Lin and Wu 2018). Our empirical results show that for passenger cars such a relationship does not exist. This could be related to the public good nature of the environment and that the individual's decision to purchase an electric vehicle to reduce environmental stress does not only affect herself. For electric buses, we find a significant and positive effect of local pollution 
on diffusion. The effect size is substantial and additional robustness tests confirm that the effect is driven by the highly polluted regions. With the increasing focus by China on policy that addresses environmental concerns (Jin et al. 2016; Feng and Liao 2016), regional governments adopt electric buses to mitigate local pollution. This result indicates that not only is green public procurement part of a more general environmental policy mix in China, but it also illustrates that regional governments react to environmental pollution and try to mitigate them.

These results have several implications for the theoretical understanding of diffusion processes, especially for eco-innovations. First, the results show that factors do not uniformly influence the diffusion process across technologies but are technology specific, as the comparison of the four different vehicle types demonstrate. In addition to technological differences, usage pattern needs to be considered for a better understanding of diffusion and design of support mechanisms, as illustrated for charging infrastructure. Second, environmental conditions can have an effect on diffusion, but this effect seems to be actor specific. Contrary to studies on willingnessto-pay results, the adoption of a clean vehicle seems not to be affected by the environmental condition at the private customer level. However, governmental actors react to environmental stress and adopt electric vehicles as a policy response. This finding indicates that externalities of competing technologies can influence adoption decisions. Third, the results for buses provide insights into the ways in which governmental decisions for public procurement are influenced. Rather than monetary factors, other factors, such as the provision of complementary infrastructure and environmental concerns, seem decisive.

The findings can be translated into policy recommendations to support the diffusion of electric vehicles and eco-innovations in general. First, subsidies to reduce vehicle prices result in their intended effect and increase the diffusion of cars. For the case of China in particular, the "Ten Cities, Thousands of Vehicles" program and its successors seem not to provide the intended effect, most likely because the subsidy level decreases over time. While decreasing support usually contributes to dynamic efficiency, it should be linked to the technological progress to allow for a stable support environment (cf. the German feedin tariff for photovoltaics, where technological progress was faster than the decrease in support). Second, non-monetary incentives can have substantial effects, as the license-plate policies for BEV cars illustrate. Reducing the incentives to use alternative technologies can be an efficient way to increase diffusion. Third, the provision of public charging infrastructure is decisive for diffusion. Governments should provide means to establish the required infrastructure and thereby consider usage pattern. The recently implemented "Guidelines for Accelerating the Plug-in Electric Vehicle Charging Infrastructure Deployment" can provide additional charging facilities and can serve as an example for other countries in terms of scale and long-term planning. Fourth, local environmental conditions influence the decision to invest in electric vehicles. Considering the support for electric vehicles in a broader environmental policy mix can be a viable option to reduce regional and, potentially, global pollution. Green public procurement should be fostered on a larger scale to mitigate climate change (Aldenius and Khan 2017). However, when implementing such policies, coordination failure needs to be considered. For example, China must address the issue that the current electricity mix is too dirty to gain overall environmental improvements (Huo et al. 2010, 2015).

The present study has several caveats and opens up room for further research. We are the first to provide an assessment of the diffusion of electric buses, but the factors that influence their diffusion are still uncertain. Further research needs to explicitly address issues of governmental decision-making to better understand the factors that influence diffusion, especially in different institutional settings. In addition, while our results provide first insights into the influence of environmental conditions on diffusion, Chinese pollution data is not reliable, so additional 
research needs to confirm these findings. Furthermore, we do not consider a mix of determinants that influence diffusion. In this respect, theoretical and empirical contributions need to provide deeper understanding of how the interaction of determinants influence diffusion. Our presented results need to be considered in light of several limitations in our analysis. We have only a limited sample of regions, so an analysis on a wider sample should improve estimation efficiency, and the use of external instruments, especially for subsidies and charging infrastructure, would improve reliability. Furthermore, Chinese data needs to be taken with care, since reported data can be or is influenced by political considerations (e.g. diffusion targets or environmental variables). Further due to limitations of available data, we are not able to measure diffusion in the strict sense-as the share of electric vehicles to conventional vehicles-but we measured it rather as the annual number of vehicle registrations. Therefore, we cannot directly account for the market size and international comparison is limited. Better data sources can mitigate such shortcomings.

\section{Appendix}


Table 5 Regions and implemented policies

\begin{tabular}{|c|c|c|c|c|c|c|}
\hline \multirow[t]{2}{*}{ Region } & \multirow[t]{2}{*}{ Region type } & \multirow{2}{*}{$\begin{array}{l}\text { Policy period } 1 \\
2010-2012\end{array}$} & \multicolumn{2}{|c|}{ Policy period 2} & \multirow{2}{*}{$\begin{array}{l}\text { Policy period } 3 \\
2016\end{array}$} & \multirow[t]{2}{*}{ Non-monetary incentives } \\
\hline & & & 2013 & $\begin{array}{l}2014- \\
2015\end{array}$ & & \\
\hline Beijing & City* & $X$ & $X$ & $X$ & $X$ & $\begin{array}{c}2011 \text { (lottery, BEV } \\
\text { exemption only) }\end{array}$ \\
\hline Chengdu & City & $\mathrm{X}^{* *}$ & $X$ & $\mathrm{X}$ & $X$ & \\
\hline Chongqing & City* & $\mathrm{X}^{* *}$ & $\mathrm{X}$ & $X$ & $X$ & \\
\hline Dalian & City & $\mathrm{X}^{* *}$ & $\mathrm{X}$ & $X$ & $X$ & \\
\hline Fujian & Province & $\mathrm{X}^{* *}$ & $\mathrm{X}$ & $\mathrm{X}$ & $\mathrm{X}$ & \\
\hline Guangzhou & City & $\mathrm{X}^{* *}$ & $X$ & $X$ & $X$ & $\begin{array}{l}2013 \text { (auction and lot- } \\
\text { tery) }\end{array}$ \\
\hline Haikou & City & $\mathrm{X}^{* *}$ & $X$ & $\mathrm{X}$ & $\mathrm{X}$ & \\
\hline Hangzhou & City & $X$ & $X$ & $X$ & $X$ & $\begin{array}{l}2014 \text { (auction and lot- } \\
\text { tery) }\end{array}$ \\
\hline Hebei & Province & $\mathrm{X}^{* *}$ & $X$ & $\mathrm{X}$ & $X$ & \\
\hline Hefei & City & $X$ & $X$ & $X$ & $X$ & \\
\hline Huizhou & City & & $X$ & $X$ & $X$ & \\
\hline Hunan & Province & $\mathrm{X}^{* *}$ & $X$ & $X$ & $X$ & \\
\hline Jiangxi & Province & $\mathrm{X}^{* *}$ & $X$ & $X$ & $X$ & \\
\hline Jilin & Province & $X$ & & $X$ & $X$ & \\
\hline Jinhua & City & & $X$ & $X$ & $X$ & \\
\hline Nanjing & City & & & $X$ & $X$ & \\
\hline Nantong & City & $\mathrm{X}^{* *}$ & & $X$ & $X$ & \\
\hline Qingdao & City & & $X$ & $X$ & $X$ & \\
\hline Shanghai & City* & $X$ & $X$ & $X$ & $X$ & $\begin{array}{l}2010 \text { (auction and lot- } \\
\text { tery) }\end{array}$ \\
\hline Shenyang & City & $\mathrm{X}^{* *}$ & & $X$ & $X$ & \\
\hline Shenzhen & City & $X$ & $X$ & $X$ & $X$ & $\begin{array}{l}2015 \text { (auction and lot- } \\
\text { tery) }\end{array}$ \\
\hline Suzhou & City & $\mathrm{X}^{* *}$ & & $X$ & $X$ & \\
\hline Tangshan & City & $\mathrm{X}^{* *}$ & $X$ & $X$ & $X$ & \\
\hline Tianjin & City* & $\mathrm{X}^{* *}$ & $X$ & $X$ & $X$ & $\begin{array}{l}2014 \text { (auction and lot- } \\
\text { tery) }\end{array}$ \\
\hline Wuhan & City & $\mathrm{X}^{* *}$ & $X$ & $X$ & $X$ & \\
\hline Xi'an & City & & $X$ & $X$ & $X$ & \\
\hline Xiangyang & City & $\mathrm{X}^{* *}$ & $X$ & $X$ & $X$ & \\
\hline Xinxiang & City & & $X$ & $X$ & $X$ & \\
\hline Yancheng & City & & & $X$ & $X$ & \\
\hline Yunnan & Province & $\mathrm{X}^{* *}$ & $X$ & $X$ & $X$ & \\
\hline Zhengzhou & City & $\mathrm{X}^{* *}$ & $X$ & $X$ & $X$ & \\
\hline
\end{tabular}

*A indicates cities which are at the same time provinces (direct-controlled municipalities)

**Indicates regions in which electric vehicles were supported only for public actors

Policy Period 1 refers to the "Ten Cities, Thousands of Vehicles" program (2009-2012). Policy Period 2 to the "Guiding Opinions on Accelerating the Promotion of the Application of New Energy Vehicles" program (2013-2015). Policy Period 3 refers to the "Notice concerning Financial Support Policy for Promotion and Application of New Energy Vehicle” program (2016-2020) 


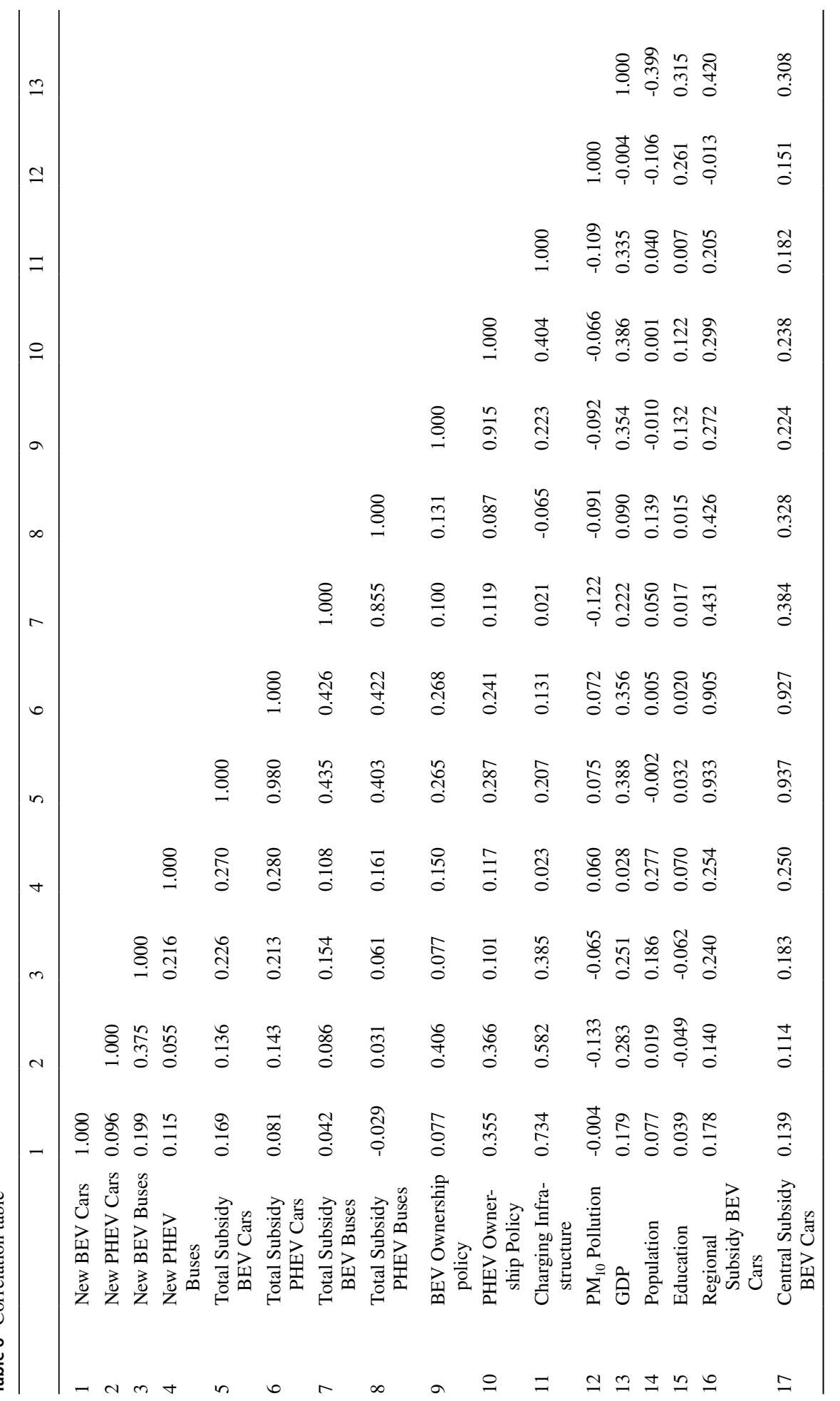




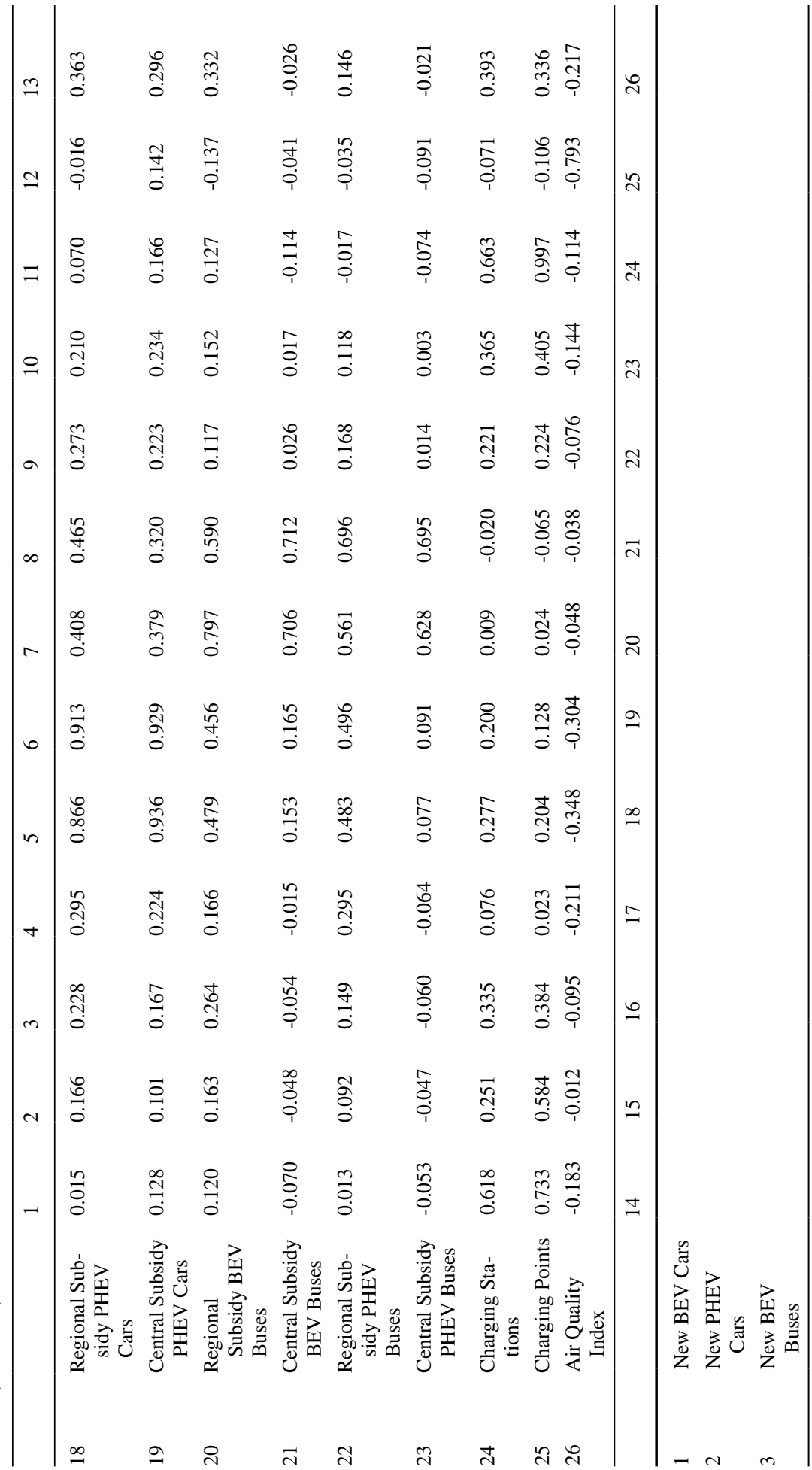




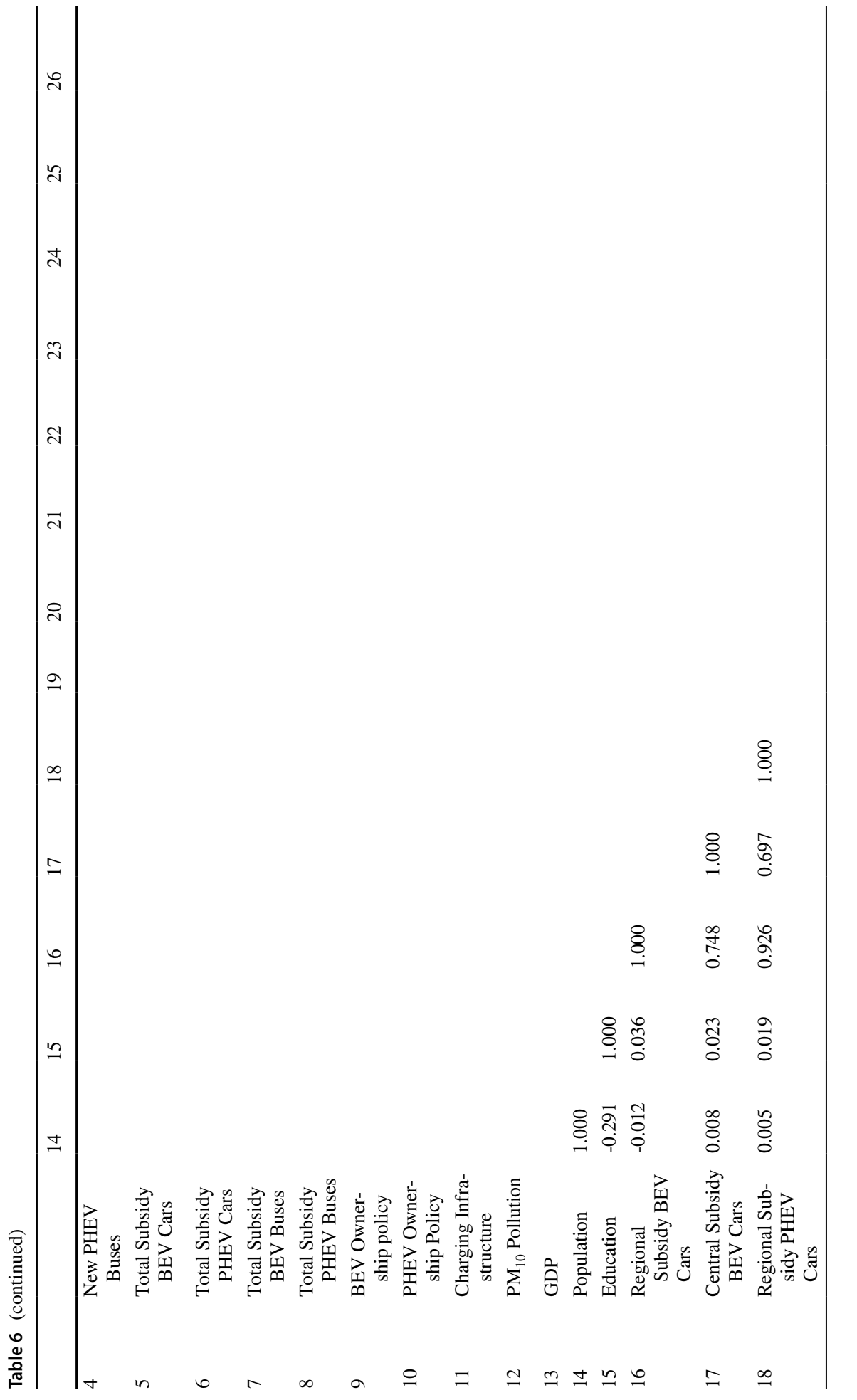

包 Springer 


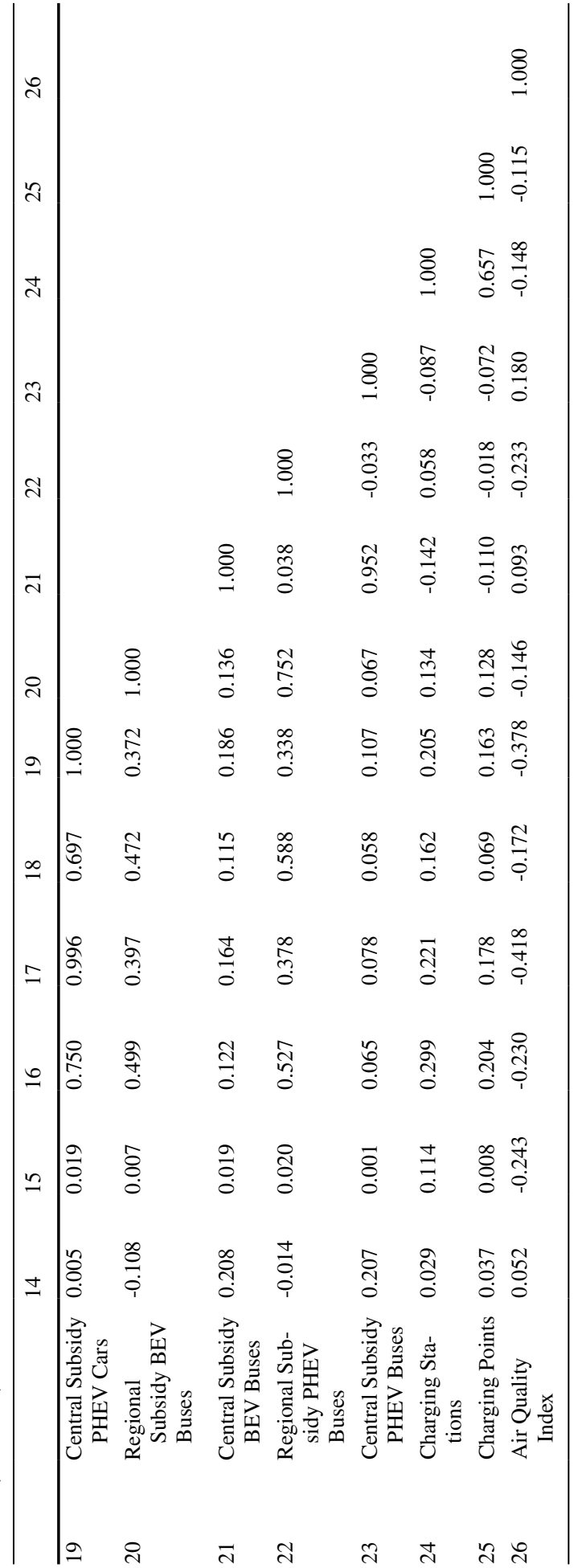


Supplementary Information The online version contains supplementary material available at https://doi. org/10.1007/s10640-021-00596-4.

Acknowledgements We are grateful for discussions by and with Uwe Cantner, Jakob Edler, Maryann Feldman, Huiwen Gong, Holger Graf, Johannes Herrmann, Bettina Peters, Faraz Riaz, Cathrin Söllner and Michael Wyrwich as well as participants at the Jena Lecture Series in Economic Geography 2018 in Jena, the University Alliance for Sustainability Spring Campus 2018 in Berlin, the $17^{\text {th }}$ International Joseph A. Schumpeter Society Conference 2018 in Seoul, the Herrenhausen Conference 2019 in Hanover and the Economics Seminar at the University Kassel in 2019 . We are grateful for comments by two anonymous reviewers.We are grateful for discussions by and with Uwe Cantner, Jakob Edler, Maryann Feldman, Huiwen Gong, Holger Graf, Johannes Herrmann, Bettina Peters, Faraz Riaz, Cathrin Söllner and Michael Wyrwich as well as participants at the Jena Lecture Series in Economic Geography 2018 in Jena, the University Alliance for Sustainability Spring Campus 2018 in Berlin, the $17^{\text {th }}$ International Joseph A. Schumpeter Society Conference 2018 in Seoul, the Herrenhausen Conference 2019 in Hanover and the Economics Seminar at the University Kassel in 2019. We are grateful for comments by two anonymous reviewers.

Funding Open Access funding enabled and organized by Projekt DEAL.

Open Access This article is licensed under a Creative Commons Attribution 4.0 International License, which permits use, sharing, adaptation, distribution and reproduction in any medium or format, as long as you give appropriate credit to the original author(s) and the source, provide a link to the Creative Commons licence, and indicate if changes were made. The images or other third party material in this article are included in the article's Creative Commons licence, unless indicated otherwise in a credit line to the material. If material is not included in the article's Creative Commons licence and your intended use is not permitted by statutory regulation or exceeds the permitted use, you will need to obtain permission directly from the copyright holder. To view a copy of this licence, visit http://creativecommons.org/licenses/by/4.0/.

\section{References}

Aldenius M, Khan J (2017) Strategic use of green public procurement in the bus sector: challenges and opportunities. J Clean Prod 164:250-257

Arellano M, Bond S (1991) Some tests of specification for panel data: monte carlo evidence and an application to employment equations. Rev Econ Stud 58(2):277-297

Arellano M, Bover O (1995) Another look at the instrumental variable estimation of error-components models. J Econometr 68(1):29-51

Arrow KJ (1962) Economic welfare and the allocation of resources for invention. In: Nelson R (ed) The Rate and Direction of Innovative Activity: Economic and Social Factors. Princeton University Press, Princeton, pp 609-625

Arthur WB (1989) Competing technologies, increasing returns and lock-in by historical events. Econ J 99(394):116-131

Baumol WJ, Oates WE (1988) The theory of environmental policy. Cambridge Univ. Press, Cambridge, 2 edition

Bleda M, del Rio P (2013) The market failure and the systemic failure rationales in technological innovation systems. Res Policy 42(5):1039-1052

Bloomberg New Energy Finance (2018) Electric Buses in Cities - Driving Towards Cleaner Air and Lower $\mathrm{CO} 2$

Blundell R, Bond S (1998) Initial conditions and moment restrictions in dynamic panel data models. J Econometr 87(1):115-143

Bond SR (2002) Dynamic panel data models: a guide to micro data methods and practice. Port Econ J 1(2):141-162

Bunch DS, Bradley M, Golob TF, Kitamura R, Occhiuzzo GP (1993) Demand for clean-fuel vehicles in california: a discrete-choice stated preference pilot project. Trans Res Part A: Policy Practice 27(3):237-253

Cantono S, Silverberg G (2009) A percolation model of eco-innovation diffusion: the relationship between diffusion, learning economies and subsidies. Technol Forecast Soc Chang 76(4):487-496

Carley S, Krause RM, Lane BW, Graham JD (2013) Intent to purchase a plug-in electric vehicle: a survey of early impressions in large US cites. Transp Res Part D: Transp Environ 18:39-45 
Cecere G, Corrocher N, Gossart C, Ozman M (2014) Lock-in and path dependence: an evolutionary approach to eco-innovations. J Evol Econ 24(5):1037-1065

Chan CK, Yao X (2008) Air pollution in mega cities in china. Atmos Environ 42(1):1-42

Chen S, Oliva P, Zhang P (2017) The effect of air pollution on migration: Evidence from china. Working Paper 24036, National Bureau of Economic Research

Chen X, Zhao J (2013) Bidding to drive: car license auction policy in shanghai and its public acceptance. Transp Policy 27:39-52

Chen Y, Jin GZ, Kumar N, Shi G (2012) Gaming in air pollution data? lessons from china. The B.E. Journal of Economic Analysis \& Policy, 12(3)

Clinton BC, Steinberg DC (2019) Providing the spark: impact of financial incentives on battery electric vehicle adoption. J Environ Econ Manag 98:102255

Coffman M, Bernstein P, Wee S (2016) Electric vehicles revisited: a review of factors that affect adoption. Transp Rev 37(1):79-93

Cowan R, Hulten S (1996) Escaping lock-in: the case of the electric vehicle. Technol Forecast Soc Chang 53(1):61-79

Dixon T (2018) 100\% - chinese city's record-smashing 16,359 electric bus fleet

Egbue O, Long S (2012) Barriers to widespread adoption of electric vehicles: an analysis of consumer attitudes and perceptions. Energy Policy 48:717-729

Egnér F, Trosvik L (2018) Electric vehicle adoption in sweden and the impact of local policy instruments. Energy Policy 121:584-596

Erdem C, Şentürk İ, Şimşek T (2010) Identifying the factors affecting the willingness to pay for fuelefficient vehicles in turkey: A case of hybrids. Energy Policy 38(6):3038-3043

Falcão EAM, Teixeira ACR, Sodré JR (2017) Analysis of CO2 emissions and techno-economic feasibility of an electric commercial vehicle. Appl Energy 193:297-307

Feng L, Liao W (2016) Legislation, plans, and policies for prevention and control of air pollution in china: achievements, challenges, and improvements. J Clean Prod 112:1549-1558

Figenbaum E, Kolbenstvedt M (2016) Learning from norwegian battery electric and plug-in hybrid vehicle users: Results from a survey of vehicle owners. Technical Report 1492/2016, TØI report

Freeman R, Liang W, Song R, Timmins C (2019) Willingness to pay for clean air in china. J Environ Econ Manag 94:188-216

Funke SA, Sprei F, Gnann T, Plötz P (2019) How much charging infrastructure do electric vehicles need? a review of the evidence and international comparison. Transp Res Part D: Transp Environ 77:224-242

Gallagher KS, Muehlegger E (2011) Giving green to get green? incentives and consumer adoption of hybrid vehicle technology. J Environ Econ Manag 61(1):1-15

Geroski PA (2000) Models of technology diffusion. Res Policy 29(4-5):603-625

Ghanem D, Zhang J (2014) Effortless perfection: do chinese cities manipulate air pollution data? J Environ Econ Manag 68(2):203-225

Gnann T, Plötz P (2015) A review of combined models for market diffusion of alternative fuel vehicles and their refueling infrastructure. Renew Sustain Energy Rev 47:783-793

Gong H, Wang MQ, Wang H (2013) New energy vehicles in china: policies, demonstration, and progress. Mitig Adapt Strat Glob Change 18(2):207-228

Goulder LH, Morgenstern RD, Munnings C, Schreifels J (2017) China's national carbon dioxide emission trading system: An introduction. Economics of Energy \& Environmental Policy 6(2):1-18

Greene WH (2012) Econometric Analysis. Pearson, New Jersey, 7 edition

Griliches Z (1957) Hybrid corn: an exploration in the economics of technological change. Econometrica 25(4):501-522

Hackbarth A, Madlener R (2013) Consumer preferences for alternative fuel vehicles: a discrete choice analysis. Transp Res Part D: Transp Environ 25:5-17

Hall BH (2006) Innovation and diffusion. In: Fagerberg J, Mowery DC, Nelson RR (eds) Oxford Handbook of Innovation, chapter 17. Oxford University Press, Oxford, UK, pp 459-484

Hansen LP (1982) Large sample properties of generalized method of moments estimators. Econometrica 50(4):1029-1054

Hardman S (2019) Understanding the impact of reoccurring and non-financial incentives on plug-in electric vehicle adoption - a review. Transp Res Part A: Policy Practice 119:1-14

Hardman S, Chandan A, Tal G, Turrentine T (2017) The effectiveness of financial purchase incentives for battery electric vehicles - a review of the evidence. Renew Sustain Energy Rev 80:1100-1111

Hardman S, Jenn A, Tal G, Axsen J, Beard G, Daina N, Figenbaum E, Jakobsson N, Jochem P, Kinnear N, Plötz P, Pontes J, Refa N, Sprei F, Turrentine T, Witkamp B (2018) A review of consumer preferences 
of and interactions with electric vehicle charging infrastructure. Transp Res Part D: Transp Environ 62:508-523

Hardman S, Tal G (2016) Exploring the decision to adopt a high-end battery electric vehicle: role of financial and nonfinancial motivations. Transp Res Record: J Transp Res Board 2572(1):20-27

He K, Huo H, Zhang Q (2002) Urban air pollution in china: current status, characteristics, and progress. Annu Rev Energy Env 27(1):397-431

Herrmann J, Savin I (2017) Optimal policy identification: insights from the german electricity market. Technol Forecast Soc Chang 122:71-90

Hidrue MK, Parsons GR, Kempton W, Gardner MP (2011) Willingness to pay for electric vehicles and their attributes. Resour Energy Econ 33(3):686-705

Howell S, Lee H, Heal A (2014) Leapfrogging or stalling out? electric vehicles in china. Technical report, HKS Working Paper No. RWP14-035

Huo H, Cai H, Zhang Q, Liu F, He K (2015) Life-cycle assessment of greenhouse gas and air emissions of electric vehicles: a comparison between china and the u.s. Atmos Environ 108:107-116

Huo H, Zhang Q, Wang MQ, Streets DG, He K (2010) Environmental implication of electric vehicles in china. Environ Sci Technol 44(13):4856-4861

IEA (2019) Global EV Outlook 2019. International Energy Agency

IPCC (2018) Global warming of $1.5^{\circ} \mathrm{C}$. An IPCC Special Report on the impacts of global warming of $1.5^{\circ} \mathrm{C}$ above pre-industrial levels and related global greenhouse gas emission pathways, in the context of strengthening the global response to the threat of climate change, sustainable development, and efforts to eradicate poverty

Ito K, Zhang S (2020) Willingness to pay for clean air: evidence from air purifier markets in china. J Polit Econ 128(5):1627-1672

Jaffe AB, Newell RG, Stavins RN(2003) Technological change and the environment. In Mäler, K.-G. and Vincent, J. R., editors, Handbook of Environmental Economics, volume 1, chapter 11, pages 461-516. Elsevier, Amsterdam

Jaffe AB, Newell RG, Stavins RN (2005) A tale of two market failures: technology and environmental policy. Ecol Econ 54(2-3):164-174

Jenn A, Azevedo IL, Ferreira P (2013) The impact of federal incentives on the adoption of hybrid electric vehicles in the united states. Energy Econ 40:936-942

Jenn A, Springel K, Gopal AR (2018) Effectiveness of electric vehicle incentives in the united states. Energy Policy 119:349-356

Ji Z, Huang X (2018) Plug-in electric vehicle charging infrastructure deployment of china towards 2020: policies, methodologies, and challenges. Renew Sustain Energy Rev 90:710-727

Jin Y, Andersson H, Zhang S (2016) Air pollution control policies in china: a retrospective and prospects. Int J Environ Res Public Health 13(12):1219

Karakaya E, Hidalgo A, Nuur C (2014) Diffusion of eco-innovations: a review. Renew Sustain Energy Rev 33:392-399

Katz ML, Shapiro C (1994) Systems competition and network effects. J Econ Perspect 8(2):93-115

Kemp R (2005) Zero emission vehicle mandate in california: misguided policy or example of enlightened leadership? In: Sartorius C, Zundel S (eds) Time Strategies, Innovation and Environmental Policy. Edward Elgar Publishing, Cheltenham

Kumar RR, Alok K (2020) Adoption of electric vehicle: a literature review and prospects for sustainability. J Clean Prod 253:119911

Lane BW, Messer-Betts N, Hartmann D, Carley S, Krause RM, Graham JD (2013) Government promotion of the electric car: risk management or industrial policy? Eur J Risk Regulat 4(2):227-245

Lelieveld J, Evans JS, Fnais M, Giannadaki D, Pozzer A (2015) The contribution of outdoor air pollution sources to premature mortality on a global scale. Nature 525(7569):367-371

Li S, Tong L, Xing J, Zhou Y (2017) The market for electric vehicles: indirect network effects and policy design. J Assoc Environ Resour Econ 4(1):89-133

Li W, Long R, Chen H, Chen F, Zheng X, Yang M (2019) Effect of policy incentives on the uptake of electric vehicles in china. Sustainability 11(12):3323

Lin B, Tan R (2017) Estimation of the environmental values of electric vehicles in chinese cities. Energy Policy 104:221-229

Lin B, Wu W (2018) Why people want to buy electric vehicle: an empirical study in first-tier cities of china. Energy Policy 112:233-241

Liu J, Diamond J (2005) China's environment in a globalizing world. Nature 435(7046):1179-1186

Liu X-H, Zhang Y, Cheng S-H, Xing J, Zhang Q, Streets DG, Jang C, Wang W-X, Hao J-M (2010) Understanding of regional air pollution over china using CMAQ, part i performance evaluation and seasonal variation. Atmos Environ 44(20):2415-2426 
Ma S-C, Fan Y, Feng L (2017) An evaluation of government incentives for new energy vehicles in china focusing on vehicle purchasing restrictions. Energy Policy 110:609-618

Matus K, Nam K-M, Selin NE, Lamsal LN, Reilly JM, Paltsev S (2012) Health damages from air pollution in china. Glob Environ Chang 22(1):55-66

Mersky AC, Sprei F, Samaras C, Qian ZS (2016) Effectiveness of incentives on electric vehicle adoption in norway. Transp Res Part D: Transp Environ 46:56-68

Metcalfe JS (1988) The diffusion of innovatoin: an interpretative survey. In: Dosi G, Freeman C, Nelson RR, Silverberg G, Soete L (eds) Technical Change and Economic Theory, chapter 25. Francis Pinter, London, pp 561-589

Münzel C, Plötz P, Sprei F, Gnann T (2019) How large is the effect of financial incentives on electric vehicle sales? - a global review and european analysis. Energy Econ 84:104493

Ou S, Lin Z, He X, Przesmitzki S (2018) Estimation of vehicle home parking availability in china and quantification of its potential impacts on plug-in electric vehicle ownership cost. Transp Policy 68:107-117

Ouyang D, Ou X, Zhang Q, Dong C (2020) Factors influencing purchase of electric vehicles in china. Mitig Adapt Strat Glob Change 25(3):413-440

Ozaki R (2010) Adopting sustainable innovation: what makes consumers sign up to green electricity? Bus Strateg Environ 20(1):1-17

Palmer K, Tate JE, Wadud Z, Nellthorp J (2018) Total cost of ownership and market share for hybrid and electric vehicles in the UK, US and japan. Appl Energy 209:108-119

Qiu Y, Zhou P, Sun H (2019) Assessing the effectiveness of city-level electric vehicle policies in china. Energy Policy 130:22-31

Rennings K (2000) Redefining innovation - eco-innovation research and the contribution from ecological economics. Ecol Econ 32(2):319-332

Rogers EM (1962) The Diffusion of Innovation. Free Press, New York, 5. (2003) edition

Rohde RA, Muller RA (2015) Air pollution in china: mapping of concentrations and sources. PLoS ONE 10(8):e0135749

Roodman D (2009) A note on the theme of too many instruments. Oxford Bull Econ Stat 71(1):135-158

Rosenberg N (1972) Factors affecting the diffusion of technology. Explor Econ Hist 10(1):3-33

Sheldon TL, Dua R (2019) Measuring the cost-effectiveness of electric vehicle subsidies. Energy Econ 84:104545

Sheldon TL, Dua R (2020) Effectiveness of china's plug-in electric vehicle subsidy. Energy Economics 88:104773

Shengyang S (2018) Trends and challenges in electric-bus development in china

Sierzchula W, Bakker S, Maat K, van Wee B (2014) The influence of financial incentives and other socioeconomic factors on electric vehicle adoption. Energy Policy 68:183-194

Sims R, Schaeffer R, Creutzig F, Cruz-Núñez X, D’Agosto M, Dimitriu D, Meza MJF, Fulton L, Kobayashi S, Lah O, McKinnon A, Newman P, Ouyang M, Schauer JJ, Sperling D, Tiwari G (2014) Climate change 2014: Mitigation of climate change. contribution of working group iii to the fifth assessment report of the intergovernmental panel on climate change. In Edenhofer, O., Pichs-Madruga, R., Sokona, Y., Farahani, E., Kadner, S., Seyboth, K., Adler, A., Baum, I., Brunner, S., Eickemeier, P., Kriemann, B., Savolainen, J., Schlömer, S., von Stechow, C., Zwickel, T., and Minx, J., editors, Climate Change2014: Mitigation of Climate Change. Contribution of Working Group III to the Fifth Assessment Report of the IntergovernmentalPanel on Climate Change, number 8, chapter Transport, pages 599-670. Cambridge University Press, Cambridge, United Kingdom and New York, NY, USA

Soto M (2009) System gmm estimation with a small sample. Technical report

Spaargaren G (2003) Sustainable consumption: a theoretical and environmental policy perspective. Soc Nat Resour 16(8):687-701

Sperling D (2018) Electric vehicles: approaching the tipping point. Bullet Atom Scient 74(1):11-18

Sundt S, Rehdanz K (2015) Consumers' willingness to pay for green electricity: A meta-analysis of the literature. Energy Economics 51:1-8

Tal G, Nicholas M (2016) Exploring the impact of the federal tax credit on the plug-in vehicle market. Transp Res Record: J Transp Res Board 2572(1):95-102

Unruh GC (2000) Understanding carbon lock-in. Energy Policy 28:817-830

Unruh GC (2002) Escaping carbon lock-in. Energy Policy 30(4):317-325

Vergis S, Chen B (2015) Comparison of plug-in electric vehicle adoption in the united states: a state by state approach. Res Transp Econ 52:56-64

Wan Z, Sperling D, Wang Y (2015) China's electric car frustrations. Transp Res Part D: Transp Environ 34:116-121 
Wang H, Kimble C (2011) Leapfrogging to electric vehicles: patterns and scenarios for china's automobile industry. Int J Automot Technol Manag 11(4):312-325

Wang N, Pan H, Zheng W (2017a) Assessment of the incentives on electric vehicle promotion in china. Transp Res Part A: Policy Practice 101:177-189

Wang Y, Sperling D, Tal G, Fang H (2017b) China's electric car surge. Energy Policy 102:486-490

Wee S, Coffman M, Croix SL (2018) Do electric vehicle incentives matter? evidence from the 50 u.s. states. Res Policy 47(9):1601-1610

Weiss M, Patel MK, Junginger M, Perujo A, Bonnel P, van Grootveld G (2012) On the electrification of road transport - learning rates and price forecasts for hybrid-electric and battery-electric vehicles. Energy Policy 48:374-393

Wells P, Lin X (2015) Spontaneous emergence versus technology management in sustainable mobility transitions: electric bicycles in china. Transp Res Part A: Policy Practice 78:371-383

Williams C (2013) Electric avenue. New Scientist 218(2922):38-41

Windmeijer F (1995) A note on $r 2$ in the instrumental variables model. J Quant Econ 11(1):257-261

Windmeijer F (2005) A finite sample correction for the variance of linear efficient two-step GMM estimators. J Econometr 126(1):25-51

Windrum P, Ciarli T, Birchenhall C (2009) Consumer heterogeneity and the development of environmentally friendly technologies. Technol Forecast Soc Chang 76(4):533-551

$\mathrm{Xu} \mathrm{L}$, Su J (2016) From government to market and from producer to consumer: transition of policy mix towards clean mobility in china. Energy Policy 96:328-340

Yuan X, Liu X, Zuo J (2015) The development of new energy vehicles for a sustainable future: a review. Renew Sustain Energy Rev 42:298-305

Zhang Q, Li H, Zhu L, Campana PE, Lu H, Wallin F, Sun Q (2018) Factors influencing the economics of public charging infrastructures for EV - a review. Renew Sustain Energy Rev 94:500-509

Zhang X, Bai X (2017) Incentive policies from 2006 to 2016 and new energy vehicle adoption in 20102020 in china. Renew Sustain Energy Rev 70:24-43

Zhang X, Liang Y, Yu E, Rao R, Xie J (2017) Review of electric vehicle policies in china: content summary and effect analysis. Renew Sustain Energy Rev 70:698-714

Zhao X, Doering OC, Tyner WE (2015) The economic competitiveness and emissions of battery electric vehicles in china. Appl Energy 156:666-675

Zheng J, Mehndiratta S, Guo JY, Liu Z (2012) Strategic policies and demonstration program of electric vehicle in china. Transp Policy 19(1):17-25

Zuev D (2018) Urban Mobility in Modern China. Springer International Publishing, Cham, Switzerland

Publisher's Note Springer Nature remains neutral with regard to jurisdictional claims in published maps and institutional affiliations. 